\title{
Nonlinear Materials for Optical Power Limiting: Characterization and Modelling
}

Hampus Lundén 


\title{
Nonlinear Materials for Optical Power Limiting: Characterization and Modelling
}

\author{
Hampus Lundén
}


(C) Hampus Lundén

ISBN 978-91-7685-113-5

ISSN 0345-7524

This thesis is in large parts based on my licentiate thesis [1].

Printed by LiU-Tryck 2019 


\section{Abstract}

High power laser pulses can be a threat to optical sensors, including the human eye. Traditionally this threat has been alleviated by colour filters that block radiation in chosen wavelength ranges. Colour filters' main drawback is that they block radiation regardless of it being useful or damaging, information is lost for wavelengths at which the filter is active. Protecting the entire wavelength range of a sensor would block or strongly attenuate the radiation needed for the operation of the sensor.

Sol-gel glasses highly doped with optically non-linear chromophores have previously shown high optical quality in combination with efficient optical power limiting (OPL) through reverse saturable absorption ${ }^{1}$ (RSA). These filters transmit visible light unless the light fluence is above a certain threshold. A key design consideration of laser protection filters is linear absorption in relation to the threshold level. A high linear absorption means that the user's view is degraded by the filter.

To model the photokinetics of RSA chromophores, the five-level population model is widely used. It consists of three singlet and two triplet levels. Model parameters relevant for OPL performance include linear absorption cross-sections, two-photon absorption (2PA) cross-sections, lifetimes, quantum yields and intersystem-crossing (ISC) times. The dominant design paradigm is to have a highly absorbing and long-lived triplet state that is quickly populated by ISC during the beginning of a laser pulse.

To simultaneously achieve a lower threshold and linear absorption a vast number of materials for self-activated filters were evaluated, either as bulk glasses or solutions. An f/5 setup was used to evaluate their OPL performance while several photophysical measurements were performed to gain an understanding of system behaviour. The first three series of methyltriethoxysilane (MTEOS) SolGel glasses were doped with gold nanoparticles either solely, or with one of two Pt-acetylide chromophores. One with shorter conjugated ligands, the second with similar but longer conjugated ligands. Finally, a series of multi-branched fluorene

\footnotetext{
${ }^{1}$ Standard nomenclature, see section 1.3.3.
} 
chromophores were evaluated in solution. Their central moiety was either an organic benzene unit or an ISC promoter in the form of para-dibromobenzene or a platinum(II)-alkynyl unit.

For the gold nanoparticle doped glasses, the lower performance Pt-acetylide with short ligands had its OPL threshold lowered at $600 \mathrm{~nm}$ while the glasses doped with only gold nanoparticles showed no OPL at all. Secondly, the enhancement was most pronounced for very low gold nanoparticle concentrations. While gold nanoparticles alone showed good OPL performance at $532 \mathrm{~nm}$, at this wavelength neither Pt-acetylide showed an obvious OPL enhancement beyond linear absorption losses from codoping with gold nanoparticles.

The improved OPL performance at $600 \mathrm{~nm}$ was attributed to stronger 2PA, by electric field enhancement from the gold nanoparticles. The lack of detectable OPL improvement for $532 \mathrm{~nm}$ and for the higher performance Pt-Acetylide chromophore with long ligands were qualitatively explained by a lower sensitivity to $2 \mathrm{PA}$ on system performance. A degraded performance from linear absorption by excess nanoparticles in front of the focus explained the weakening of the enhancement at higher gold nanoparticle concentrations.

All three fluorene chromophores, including the chromophore without a central ISC promoter, showed broadband OPL through the visible spectrum. The OPL performance of the two chromophores with ISC promoters was expected considering their transient absorption at microsecond time-scales. For the fluorene chromophore without an ISC-promoter, ultra-fast transient absorption was used to identify singlet excited state absorption as the source of the OPL performance.

Both of these series of experiments demonstrate how a simplistic view of simply increasing desired photophysical parameters, e.g. effective 2PA cross-section or ISC quantum yield, do not always result in a noticeable increase in system performance. By employing numerical population models it was possible to identify which parameters had the highest impact on OPL performance. 


\section{Populärvetenskaplig sammanfattning}

Laserpulser med hög effekt kan vara ett hot mot optiska sensorer, inklusive det oskyddade ögat. Traditionellt har detta hot hanterats med färgfilter som stoppar strålning inom valda våglängdsband. Färgfilters huvudsakliga begränsning ligger i att de tar bort strålning oberoende av om den är användbar eller skadlig, att information försvinner för de våglängder filtret skyddar för. Skydd över hela det våglängdsband en sensor verkar i skulle stoppa eller kraftigt försvaga strålningen som sensorn behöver för att fungera.

Sol-gel glas högdopade med optiskt icke-linjära molekyler har tidigare visat hög optisk kvalité i kombination med en effektiv optisk effektbegränsning (OPL) via omvänd blekning (RSA). Dessa filter transmitterar synligt ljus så länge ljusets fluens (pulsenergi per area $\left[\mathrm{J} \mathrm{cm}^{-2}\right]$ ) inte ligger över en viss begränsningsnivå. En nyckelfaktor i designen av laserskyddsfilter är linjärabsorption kontra begränsningsnivå. Genom att öka kromoforkoncentrationen så kan begränsningsnivån sänkas till kostnad av ökad linjärabsorption. Detta betyder dock att användarens omvärldsuppfattning genom filtret riskerar att minska.

För att modellera fotokinetiken av RSA-molekyler har femnivåpopulationsmodellen varit vida använd. Den består av tre singlet-nivåer och två tripletnivåer. Modellparametrar relevanta för OPL-prestanda innefattar kvantverkningsgrader, olika övergångars linjärabsorptionstvärsnitt, tvåfotonsabsorptionstvärsnitt och livstider samt halveringstider för överföring mellan singlet och triplettillstånd. Den dominanta designparadigmen är att ha ett hög- absorberande och långlivat tripletläge som snabbt populeras i början av en laserpuls.

För att samtidigt uppnå en lägre begränsningsnivå och lägre linjärabsorption utvärderades ett flertal självaktiverade filter, antingen i form av glas eller i vätskelösning. En f/5-uppställning användes för att utvärdera deras OPLprestanda medan en mängd fotofysiska mätningar utfördes för att få en förståelse för deras systembeteende. De tre första serierna av MTEOS Sol-Gel glas var dopade med guldnanopartiklar antingen enbart, eller med en av två $\mathrm{Pt}(\mathrm{II})$ - 
acetylidmolekyler. Den första hade kortare konjugerade ligandarmar, den andra var liknande men hade längre ligandarmar. Slutligen utvärderades en serie av flerarmade flourenmolekyler i vätskelösning. Deras centrala enhet bestod antingen av en organisk bensenring eller en ISC-gynnare i form av para-dibromobensen eller en $\mathrm{Pt}(\mathrm{II})$-acetylidenhet.

Guldnanopartiklarna kunde förstärka OPL-prestandan för enbart den mindre effektiva korta Pt(II)-acetylidmolekylen på $600 \mathrm{~nm}$ men ej $532 \mathrm{~nm}$. Filtren dopade med enbart guldnanopartiklar visade god prestanda på $532 \mathrm{~nm}$ men ingen på $600 \mathrm{~nm}$. Alla tre fluorenmolekyler visade OPL genom det synliga spektrat, även den molekylen utan ISC-gynnare.

Både dessa serier experiment demonstrerar hur ett förenklat angreppsätt med att enbart öka eftertraktade fotofysiska parametrar, t.ex. effektivt 2PA-tvärsnitt eller ISC-kvantverkningsgrad, inte alltid resulterar i märkbart ökad systemprestanda. Genom att använda numeriska populationsmodeller visas hur det är möjligt att identifiera vilka parametrar som har den största inverkan på OPLprestanda. 


\section{Preface}

This PhD thesis summarizes my studies at IFM LiU (The Department of Physics, Chemistry and Biology at Linköping University) and FOI (Swedish Defence Research Institute). My studies has been conducted as a part of my ordinary work as a research engineer at FOI, primarily focusing on protection against lasers.

My work on laser protection began after researchers at FOI lead by C. Lopes had discovered an unexpected and peculiar optical power limiting (OPL) performance enhancement at $600 \mathrm{~nm}$ laser wavelength from adding minute amounts of gold nanoparticles to Pt-Acetylide doped sol-gel glass. OPL measurements had shown that the optimal concentration of gold nanoparticles corresponded to a mean inter-particle distance of several micrometers.

The origin of the enhancement needed to be identified to answer the questions of how and if the effect could be used to enhance the OPL performance of other filters. Furthermore, an inherent goal of my $\mathrm{PhD}$ studies is to develop and consolidate FOI's capability to design new laser protection filters. Finally, an important objective not to be forgotten is to maintain the cooperation with our university partners.

Doping sol-gel bulk glasses with high concentrations of Pt-Acetylide chromophores while retaining the ability to polish the glasses to optical quality had previously been solved in cooperation with Prof. Parola's group at ENS de Lyon [2]. While their group focused on the production of the bulk materials, chromophores and gold nanoparticles, our group polished the glasses (L.-G. Heimdal) and characterized their optical properties.

A long standing cooperation also exists with my supervisor Prof. M. Lindgren from NTNU (Norwegian University of Science and Technology). In this constellation Prof. M. Lindgren and his group has focused on the photophysics and advanced spectroscopic techniques. He is currently also an adjunct professor at LiU.

As a first step in my studies, I travelled to NTNU in Trondheim to learn how to do photophysical measurements on the glasses. While analysing the fluorescence 
and phosphorescence lifetimes and relative spectral intensity of the chromophore, a lack of pattern was discerned across the series of different shape and concentration of gold nanoparticles. This contradicted many quenching based models proposed to explain the performance enhancement from low concentrations of gold nanoparticles.

At this point our team was at a loss regarding on how this mechanism worked. To increase the number of parameters acting as constraints on any potential future models, it was decided to expand the already large series of glasses. Two subseries were added, one identical to the previous series but only doped with gold nanoparticles and a second smaller one doped with both gold nano-particles and an alternative more high performance chromophore.

I and C. Brännlund then made additional OPL measurement on the glasses. The results for the original series of glasses was reproduced (for the second time). While the results for the glasses solely doped with gold nanoparticles showed good performance at $532 \mathrm{~nm}$ laser wavelength, the results contradicted models based on superposition of OPL from the chromophore and nanoparticles. The glasses doped with gold nanoparticles and an alternative high performance chromophore showed excellent performance at $600 \mathrm{~nm}$ but no obvious non-linear OPL performance increase from gold nanoparticles. While disappointing, these findings would later turn out to be vital in finding a model explaining the phenomenon.

C. Lopes performed the UV-Vis spectral measurements on the glasses. The spectra showed well defined gold nanoparticle plasmon peaks for all glasses. Though for bipyramidal gold nanoparticles co-doped with the alternative chromophore there was a peak wavelength shift with nanoparticle concentration, indicating an uneven distribution of gold nanoparticles $[3,4]$.

While trying to find a satisfying model explaining our experimental results we decided that the results from the glasses only with gold nano-particles was interesting in their own right. With ellipsometry, Z. Ghadyani and Prof. M. Kildemo found an interesting self-orientation of bipyramidal gold nanoparticles in the glasses. Though no interesting pattern in regards to enhancement of OPL was found in the ellipsometry data.

I decided to also use an integrating sphere to see if the OPL of the glasses only doped with gold nanoparticles showed OPL due to non-linear scattering as for gold nanoparticles in solution [5]. Due to the expected angle dependence on scattering from a gold nanoparticle [6-8], I was not comfortable in using the more standard Z-scan [9] method. A secondary goal was to detect any strong second harmonic generation. The measurements were consistent with non-linear scattering as a mechanism for OPL in the glasses only doped with gold nanoparticles. No strong second harmonic generation was found, again removing a potential model of OPL enhancement by gold nanoparticles. (Which seemed promising after I developed a model with input from Prof. Patrik Norman.) I thank T. Hallberg for helping in the design of an integrating sphere working in the UV-Vis range. I thank C. Brännlund for taking part in the measurements and practical setup of the experiment.

For the second article the original series of glasses was investigated. Prof. M. Lindgren and A. A. El-Amay performed a series of photophysical measurements 
on the chromophore and gold nanoparticles in solution, including excited state absorption. They showed that the excited state absorption increased by gold nanoparticles, secondly that gold nanoparticles quench the triplet state of the chromophore. Though, due to the difference in surrounding medium between solution and sol-gel glass the quenching explanation could not be applied on the glasses. Such a solution could not explain the photophysical results for the glass samples. A new model had to be developed.

Thanks to the two-photon absorption spectra of two similar chromophores recently published by M. G. Vivas et al.[10, 11], in combination with an analytical model of field enhancement by K. Tanabe [12] and the concept of feeding a population model the field enhancement field by S. Fischer et al. [13] it was possible for me to create a qualitative model describing system behaviour using photophysical parameters of very similar chromophores published by Rogers et al. [14]. By modeling the relative absorption enhancement from field enhancement of two-photon absorption it was possible to show that the gold nanoparticles caused the highly absorbing triplet state to be populated more quickly during the leading edge of the pulse.

For the third article the lack of obvious enhancement had to be explained not to discredit the model from the second article. My hypothesis was that a more efficient population of the triplet state in the better performing alternative chromophore would cause the field enhancement of two-photon absorption to have less of an impact. Since some relevant photophysical parameters of a very similar chromophore were missing from the literature and we were unable to measure them with meaningful precision in bulk glass, some parameters had to be estimated. Prof. M. Lindgren suggested the linear absorption being larger due to red-shift of the UV-absorption peak of the alternative relative to the original chromophore. Postulating a 10x increase of the very weak linear absorption of the original chromophore showed a marked decrease in OPL enhancement.

The path leading to the creation of this model was not straight. For brevity I've not included all tested hypotheses and measurements. Working with the philosophy "When you have found something unexpected, you are most probably doing something wrong.", I've had ample opportunity to scrutinize our experimental methods. In my licentiate thesis I therefore had chosen to include a frank and thorough investigation of potential weaknesses in our previous OPL measurement protocol [1]. I also identified several potential pitfalls that I believed far too many workers in the OPL field ignored. Working with the philosophy "When other people are doing it wrong, you have probably misunderstood something", I wanted to test my ideas. This wish resulted in a tutorial article explaining how to evaluate candidate molecules for OPL. Prof. M. Lindgren and E. Glimsdal chipped in on advanced photophysical measurement techniques. In large parts with the help of C. Lopes' long expertise in the field I found that many of my objections to current OPL evaluation techniques had if not already been investigated several decades ago (often in obscure conference proceedings) at least been touched upon by earlier authors. Going through this treasure trove of old publications was a both humbling and rewarding experience. I find it interesting, that in this day and age, even the experimental physical sciences can be advanced by reference to 
old authorities. I wonder if this phenomenon again will grow in importance thanks to modern search engines and an ever increasing body of scientific literature.

As in the licentiate thesis I've chosen to include and test a selection of alternative hypotheses for which I explain why they are less probable than the twophoton field enhancement model. I choose to include this discussion to strengthen my discussion about time-resolved relative absorption enhancement from changing a specific photophysical parameters. Not only was this methodology used successfully for explaining the enhancement, and lack there of, on OPL from gold nanoparticles, it was also used as a pedagogical tool in the tutorial article.

For the last article three multi-branched fluorene molecules from C. Andraud's group at ENS Lyon were investigated. The purpose of this series of molecules was to investigate the effect of different ISC promoters on the OPL performance on molecules with a large amount of 2PA moieties. Prof. M. Lindgren and his master student D. K. Hopen [15] had beforehand investigated the photophysics of these molecules. D. K. Hopen also assisted in the wavelength scanned OPL measurements.

To explain the good OPL performance of the fluorene molecule without an ISC promoter, help was needed from Prof. T. Pullerits group at Lund University. Together with I. Minda and P. Chabera we made the necessary ultra-fast transient absorption spectroscopy measurements and analysed the data. J. Uhlig at Lund University is thanked for giving me a quick primer on how to do model fitting for the spectrally resolved transient absorption data, which would prove useful when I further developed I. Minda's decay models. While much more measurements would be necessary to develop a meaningful numerical population model of the fluorene molecules, the ultra-fast transient absorption spectroscopy still allowed us to attribute the OPL performance to singlet excited state absorption.

This turned out a serendipitous discovery since I was able to tie all the articles together. This since hampering the ISC pathway did not have the negative effect on OPL as the microsecond transient absorption measurements had indicated. The gold nanoparticle enhancement of 2PA only showed a noticable effect on system performance while $2 \mathrm{PA}$ was a limiting factor. The multi-branched fluorene molecules showed less sensitivity to ISC times since they showed reverse saturable absorption both in the singlet and triplet states. This thesis shows that a naive strategy of simply increasing wanted photophysical parameters do not always work. An understanding of which parameters are performance limiting for a specific molecule can be reached by a combination of photophysical measurements and numerical population modelling.

This thesis is in large parts based on my licentiate thesis [1], in particular chapter 1 and 4 . Chapter $2 \& 3$ are a summary of article 4 [16], while also reusing parts of the licentiate thesis. Chapter 4 is more than a summary of the first three articles since it also ties them together into a larger picture [17-19]. Chapter 5 is a summary of article 5 [20]. Due to the wide range of skills necessary for the articles included in this thesis, each group was responsible for their parts of the articles. For all of these articles I have had a central part in the writing. For the first article C. Lopes did most of the writing outside of experimental procedure and results. Prof. Parola's team had the lead role in writing the second article. 


\section{Acknowledgements}

I want to thank my university supervisor, Prof. M. Lindgren. Not only for acting as any good supervisor should, but also taking the extra time and effort to advice me during his parental leave. His experience in photophysics, laboratory work, and supervising $\mathrm{PhD}$ students has been invaluable.

The efforts of my FOI project leader C. Lopes can not be ignored. He has not only been a project leader, but also as a secondary supervisor of my studies. He has always been able to combine the requirements of utility to the project with the needs of my studies, finding ways to create win-win situations. C. Lopes has taught me about chromophores, sol-gel glasses and much about the fine craft of scientific writing.

The head of department at FOI, M. Armgarth, is thanked for his insistence on me focusing on my studies while other projects vied for my attention. Without his support my studies would not have been possible.

My colleague C. Brännlund is thanked for teaching me how to perform optical power limiting measurements. He also wrote the computer code for our laboratory's optical power limiting setup.

Prof. S. Parola and his group at ENS de Lyon is thanked for their substantial part in this work. Since I consider myself primarily an experimentalist, interesting samples is of utmost importance for my work. The very long series of glasses required for this work, in combination with their large effort on the articles is strongly appreciated.

I. Minda, P. Chabera and Prof. T. Pullerits is thanked for saving the article about the fluorene molecules. Without access to their expertise and laboratory resources, too many unknowns and uncertainties would have remained for publication.

Prof M. Lindgren, M. Armgarth and C. Lopes are thanked again for their help with proofreading this thesis.

I'm very grateful for the funding from the Swedish Armed Forces allowing me to pursue my $\mathrm{PhD}$ studies while working at FOI. 

1 Introduction 1

1.1 The laser threat . . . . . . . . . . . . . . . . . 2

1.2 Self-activating filters . . . . . . . . . . . . . . . . 3

1.3 The photophysics of optical power limiting . . . . . . . . . . 5

1.3.1 Classes of optical power limiting . . . . . . . . . . 5

1.3.2 Two-photon absorption .................. 6

1.3.3 Reverse saturable absorption ... . . . . . . . . . 6

1.3.4 Luminescence . . . . . . . . . . . . . . . . . . . . . 7

1.4 Optical design . . . . . . . . . . . . . . . . . . . 7

1.4.1 Laser focus size . . . . . . . . . . . . . 8

1.4.2 Optical system design for optical power limiting . . . . . 8

1.5 Chromophores for optical power limiting . . . . . . . . . . . 9

1.5.1 Pt(II)-acetylides . . . . . . . . . . . . . . . . . . . . . . . . . . . . . . . . .

1.5 .2 Fluorenes . . . . . . . . . . . . . . . . 11

1.6 Sol-Gel glasses . . . . . . . . . . . . . . . . . . . . . . . . . . . . . 12

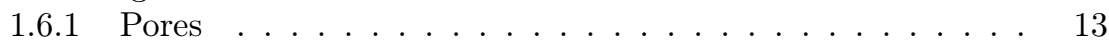

1.7 Gold nanoparticles . . . . . . . . . . . . . . . . . 13

1.7.1 Enhancement of chromophores . . . . . . . . . . 14

2 Population models $\quad 17$

2.0.1 Conversion of units . . . . . . . . . . . . 19

3 Characterization of OPL materials $\quad 21$

3.1 Optical Power Limiting Measurements . . . . . . . . . . . . . . . 21

3.1.1 Intensity scanning a.k.a. OPL measurement . . . . . . . . 21

3.1.2 Z-scan measurements. . . . . . . . . . . . . . . 25

3.2 Photophysical measurements . . . . . . . . . . . . . . . . . 27

3.2.1 Linear absorption . . . . . . . . . . . . . . . . . 27

3.2.2 Luminescence . . . . . . . . . . . . . . . . . . . . 27 
3.2.3 Microsecond transient absorption . . . . . . . . . . . . . . . 29

3.2.4 Ultra-fast transient absorption . . . . . . . . . . . . . . . 29

4 Gold nanoparticle glasses $\quad 31$

4.1 Summary of the results . . . . . . . . . . . . . . . 31

4.1.1 Glasses with only gold nanoparticles . . . . . . . . . . 31

4.1.2 Glasses with gold nanoparticles and $\mathrm{PE} 2-\mathrm{CH}_{2} \mathrm{OH}$. . . . . . 33

4.1.3 Glasses with gold nanoparticles and $\mathrm{PE} 3-\mathrm{CH}_{2} \mathrm{OH}$. . . . . . 33

4.2 Population Model . . . . . . . . . . . . . . . . 34

4.2.1 Two-photon field enhancement . . . . . . . . . . . 36

4.2.2 Absorption enhancement factor . . . . . . . . . . . . 37

4.2.3 Linear absorption before the focal point . . . . . . . . . 38

4.2.4 Potential pitfalls of the model . . . . . . . . . . . . . 39

5 Fluorene molecules $\quad 41$

5.1 Results and Discussion . . . . . . . . . . . . . . . . 41

5.1.1 Ultra-fast transient absorption measurements . . . . . . . . 43

5.2 Conclusions ...................... . . 43

6 Conclusions $\quad 45$

$\begin{array}{lll}7 & \text { Errata } & 47\end{array}$

$\begin{array}{lr}\text { Bibliography } & 49\end{array}$

$\begin{array}{ll}\text { Paper I } & 57\end{array}$

$\begin{array}{ll}\text { Paper II } & 69\end{array}$

$\begin{array}{lr}\text { Paper III } & 81\end{array}$

$\begin{array}{ll}\text { Paper IV } & 91\end{array}$

$\begin{array}{lr}\text { Paper V } & 107\end{array}$ 


\section{CHAPTER 1}

\section{Introduction}

Optical power limiting (OPL) is a nonlinear optical effect, attenuating optical radiation more strongly at higher radiation levels. Optical power limiting is useful for multiple applications including eye protection and self-activating optical switches [21]. The purpose of this work is to find ways to enhance this attenuation and evaluate candidate filters.

This introduction chapter will first describe the laser threat from an eye/sensor safety perspective, the application motivating this work. The next section, 1.2, explains why the properties of the laser threat invites a solution based on selfactivating filters. In section 1.3 an overview of mechanisms for optical power limiting is given.

In the optical power limiting research field the the optically non-linear molecules are often called chromophores. This apparent misnomer is apt since the dye molecules in some glasses can be covalently bound their host matrix. (See section 1.6 for Westlund's classification of different host matrices.) The chromophores that were codoped with gold nanoparticles, $\mathrm{PE} 2-\mathrm{CH}_{2} \mathrm{OH}$ and $\mathrm{PE} 3-\mathrm{CH}_{2} \mathrm{OH}$, are very similar to the Pt-acetylides PE2 and PE3 [18, 19]. Both PE2 and PE3 have been well characterized and reported about in the literature [10, 11, 14]. A summary of relevant photophysical parameters from the literature is given in section 1.5.1. Background information for the multi-branched fluorene molecules are presented in 1.5.2

Bulk glasses are preferable for practical optical power limiting devices $[2,16$, 22]. Thin films are susceptible to surface damage [23] and misalignment of the beam waist [24]; suspensions to agglomeration or precipitation [24] and solutions to breakdown products fouling the cuvette surfaces [25]. Sol-Gel glasses have been sucessfully used to create bulk filters with extremely high concentrations of chromophores [2]. Sol-gel glasses have also proven to be versatile since they can be doped with gold nano-particles and/or high concentrations of Pt-ethynyl 
chromophores while retaining their ability to be polished for optical use $[2,17$, 18]. A short overview of sol-gel glasses relevant to the matrix of the glasses used in this work is given in section 1.6.

A short introduction to the physics of gold nanoparticle in nonlinear optics is given in section 1.7 .

\subsection{The laser threat}

Not long after the discovery of the laser the importance of laser safety was understood due to the damage potential to human eyes [26-28]. From a military perspective, the use of laser technology has caused both accidental and intentional damage to human eyes $[29,30]$. While international law protects the unenhanced human eye from intentional permanent damage, the legal protection is far from complete [30].

Traditionally partial protection has been achieved by eye-patches, mono-ocular optics and colour filters [30]. Colour filters have the draw-back of degrading the image [30, 31]. A colour-degraded image induce varying degrees of "induced colour blindness" [32]. Colour distortion is unwanted for laser protection [33-35]. Protection from lasers with tunable wavelengths is hard to achieve by colour filters [35].

When evaluating different methods for protection against lasers, multiple threat parameters are of importance. When evaluating incoming radiation from a point source, the most important parameters are:

Pulse energy Maximum incident energy before failure of a sensor is a central parameter for describing sensor susceptibility to laser damage [21]. The limit is often expressed in $\mathrm{J} \mathrm{m}^{-2}$ on the entrance pupil of the optical system (pupil for the human eye). Note that sometimes it is expressed as fluence on the detector (retina in the eye).

Peak power Combined with pulse energy, another central parameter is peak power received by a sensor [21]. It is often expressed as irradiance in $\mathrm{W} \mathrm{m}^{-2}$. Again, a distinction between entrance pupil and detector surface needs to be made.

Pulse length Shorter pulse length with the same pulse energy results in higher peak power. For the human eye the dominant damage mechanism and thresholds depend on pulse length [36].

Pulse shape OPL performance also depends on temporal pulse shape [21], which is important for Z-scan measurements [9, 37]. (see 3.1.2)

Continuous power For a train of multiple laser pulses the average irradiance is also important to consider [36].

Wavelength Maximum allowable exposure depend on the wavelength of the laser radiation [36]. Secondly, OPL performance can depend on wavelength. 
Beam quality A laser beam of lower quality will not be focused into as small a spot as a perfect gaussian beam. This mean that in many cases the threat to the sensor would be lower due to lower fluence/irradiance compared to a diffraction limited beam. This is an important parameter when interpreting Z-scan measurements [38]. (see 3.1.2)

The main physical mechanisms causing damage to the human eye are thermoacoustic transients, thermal effects and photochemical processes [36]. Thermoacoustic transients are mainly relevant at pulses in the nanosecond regime or shorter, thermal effects in the intermediary $0.1 \mathrm{~s}$ to $10 \mathrm{~s}$ range and photochemical for long term exposure [36].

According to Swedish workplace safety regulations, the maximum permissible single pulse exposure for nanosecond pulses in the visible wavelength range is $5 \mathrm{~mJ} \mathrm{~m}^{-2}$ [36]. A $7 \mathrm{~mm}$ diameter pupil results in a maximum pulse energy of $0.2 \mu \mathrm{J}$, in agreement with other sources [21]. The filters investigated in this work are optimized for nanosecond pulses of visible light.

\subsection{Self-activating filters}

No information can travel faster than the speed of light [39]. This means that the connection between the triggering and attenuating mechanism of a filter must be shorter than it takes any damaging levels of radiation to reach the attenuation mechanism, which is especially important when dealing with pulses in the nanosecond regime or shorter [7]. By choosing a laser protection method that is self-activating this constraint can be bypassed [7]. A secondary advantage of selfactivating filters is lowering the complexity of the laser protection system, avoiding the need for active feedback [7].

Dini et al.'s comprehensive review of the subject summarize a wide variety of materials proposed as optical power limiters, including but not limited to nanocrystaline materials, metal nanoparticles, hybrid organic-inorganic materials such as Pt-ethynyls and carbon based materials like graphene [21]. The behaviour of an ideal optical power limiter, in this case a reverse saturable absorber (section 1.3), is shown in figure 1.1 .

The filters investigated in the first part of this work are MTEOS sol-gel glasses doped with gold nanoparticles (section 1.7) and/or platinum-acetylides (section 1.5.1) [17-19]. Due to the high clamping level of today's materials the laser pulse needs to be focused into the material to sufficiently lower the clamping level, see figure $1.2[40]$.

The multibranched fluorene molecule dyes investigated in the second part of this work were in solution. Further work is necessary to incorporate these molecules in a glass matrix. 


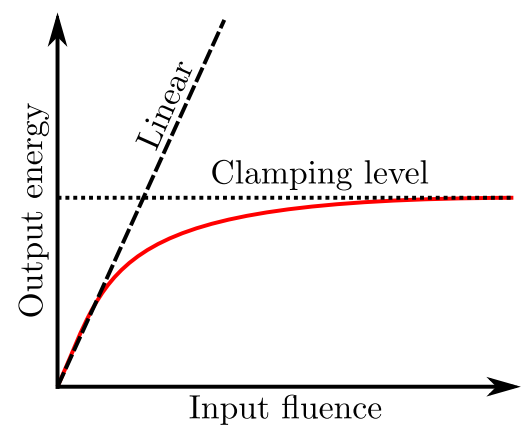

Figure 1.1. An ideal reverse saturable absorber according to multiple sources $[21,31$, 40]. The dashed line show the transmittance of a linear material or a reverse saturable absorber in its linear regime. The dotted line shows the so called clamping level of the filter, preferably below the damage threshold of the detector. The red line shows the input fluence versus output energy characteristics of an ideal reverse saturable absorber.
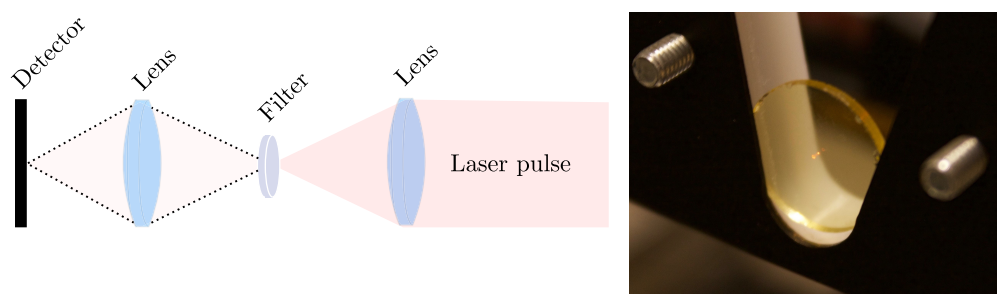

Figure 1.2. To achieve optical power limiting from a self-activating filter the laser pulse needs to be focused into the material [40]. The left drawing shows a typical optical design for an RSA based self-activated filter. The right image shows a nanosecond pulse focused into a self activated filter. Notice the multiple reflections from the glass surfaces. 


\subsection{The photophysics of optical power limiting}

There are multiple potential mechanisms to achieve optical power limiting by selfactivating filters [21]. In this section different classes of optical power limiting will first be defined and compared from a functional perspective.

\subsubsection{Classes of optical power limiting}

Functionally, self activated optical power limiting in bulk materials can be divided into three classes, nonlinear scattering, nonlinear refraction and nonlinear absorption. This classification scheme for optical power limiting materials is derived considering how a material can be optically described.

In linear optics a material can be described by a complex index of refraction $N(\lambda)=n(\lambda)+i k(\lambda)$, where $n=\sqrt{\epsilon}$ is the index of refraction, $k$ the extinction coefficient and $\lambda$ the wavelength [41]. If inhomogeneities of $N$ in a material is not significantly smaller than $\lambda$, scattering can occur [41].

All of these three parameters can be varied nonlinearly [7, 21]. Since these nonlinear effects can occur simultaneously it is important to distinguish between them when analyzing experiments $[7,21]$.

Another useful classification scheme is the distinction between instantaneous and accumulative nonlinearities [7]. Instantaneous nonlinearities depend on intensity $\left(\mathrm{W} \mathrm{cm}^{-2}\right)$ while accumulative nonlinearities depend on fluence $\left(\mathrm{J} \mathrm{cm}^{-2}\right)[7]$.

\section{Nonlinear refraction}

When light traverses a medium with changes in the refractive index, the light might be refracted according to Snell's law [41].

Different mechanisms for nonlinear refraction include thermal lensing or carrier generation leading to an optically induced Kerr-effect [7, 21]. By placing an aperture after the self-activating filter, optical power limiting can be achieved due to self-(de)focusing [7, 21].

The photorefractive effect can be used for optical power limiting [7]. The mechanism is explained by a grating of refractive index variations formed by the electro-optic effect from mobile carriers excited by an interference pattern of two coherent beams [42]. Optical power limiters employs the photorefractive effect to cause beam fanning of coherent light [7].

A potential strength of filters based on nonlinear refraction is a lower susceptibility to damage [7].

\section{Nonlinear absorption}

With nonlinear absorption excess radiation is absorbed by the filter. Assuming a low fluorescence and phosphorescence quantum yield the amount of removed radiation again being collected by following optical elements is lowered. Two examples of mechanisms are two-photon absorption (section 1.3.2) and reverse saturable absorption (section 1.3.3) [7, 21]. 


\section{Nonlinear scattering}

Radiation can induce scattering centers in a material resulting in nonlinear scattering [7]. Metal nanoparticles in solution can act as scattering centers due to microplasmas forming around them during a laser pulse [21, 43]. Though in solid materials permanent damage is an expected problem [7].

Scattering centers much smaller than the wavelength can be described by Rayleigh scattering [44]. The scattering and absorption of spherical metal nanoparticles has been described by Mie theory [45]. Mie scattering has been used to explain the microplasma scattering in carbon-black suspensions [46].

A practical drawback of nonlinear scattering is that the optics after the filter will collect a part of the scattered light [34]. For simple calculations regarding performance limits in the design of optical systems employing nonlinear scattering for laser protection, see section 1.4.2.

\subsubsection{Two-photon absorption}

Two-photon absorption (2PA) is an instantaneous nonlinearity where the energy from two photons is absorbed [7]. Two-photon absorption was first postulated by Göppert-Mayer in 1931, though required the development of the laser for real world applications [21, 31]. The nonlinear absorption coefficient, $\beta$, can be described by

$$
\begin{gathered}
\alpha(I)=\alpha_{0}+\beta I \\
-\frac{\partial I}{\partial z}=\alpha_{0} I+\beta I^{2}
\end{gathered}
$$

$[7,31,40]$. A more in depth quantum mechanical description of the mechanism can be found in Yariv's introductory quantum electronics book [47]. The molecular 2PA cross-section is usually given in GM (Göppert-Mayer), see section 2.0.1.

Two-photon absorption has been used as a mechanism for optical power limiting [7, 21]. Since two-photon absorption depend on intensity, $I$, instead of fluence the mechanism is not expected to give adequate laser protection for nanosecond pulses or longer [7, 31]. But in combination with reverse saturable absorption (section 1.3.3) two-photon absorption has potential for protection against longer pulses [31, 40]. Population modelling (chapter 2) has shown that the presence of two-photon absorption can lower the clamping level of reverse saturable absorbers [40].

\subsubsection{Reverse saturable absorption}

Reverse saturable absorption is an accumulative nonlinear mechanism (depends on fluence, $F\left[\mathrm{~J} \mathrm{~cm}^{-2}\right]$ ) used for optical power limiting [7, 21, 31, 40]. Most relevant chromophores for reverse saturable absorption can be described by a five-level population model, see figure $1.3[31,40]$. When a chromophore in its ground state, $S_{0}$, absorbs a photon an electron is excited into the higher singlet state $S_{1}$. If the inter system crossing time, $\tau_{i s c}$, is short compared to fluorescence and quenching, 


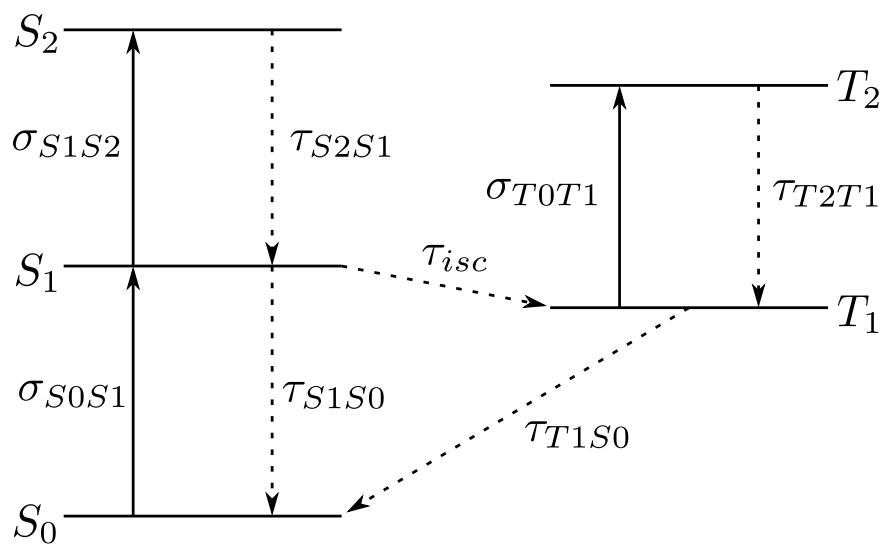

Figure 1.3. Five level Jablonski diagram of a reverse saturable absorber [7, 31, 40].

$\tau_{S 1 S 0}$, the electron might reach the triplet state, $T_{1}$. When the absorption cross section of the triplet state is much larger than the singlet state, $\sigma_{T 1 T 2} \gg \sigma_{S 0 S 1}$, the chromophore can act as an optical power limiter [21,31, 40]. Often the relaxation times of $S_{2}$ and $T_{2}$ are assumed fast enough that these levels can be ignored [31, 40]. Long enough triplet lifetime, $\tau_{T 1 S 0}$, is important for reverse saturable absorption of less intense light sources [48]. RSA can also take place in the singlet state, were $\sigma_{S 1 S 2} \gg \sigma_{S 0 S 1}$, e.g. in fluorene based molecules $[49,50]$.

\subsubsection{Luminescence}

When investigating RSA molecules, luminescence can bring light to the internal photokinetics of the molecule. Radiative relaxation from the $S_{1}$ and $T_{1}$ state cause fluorescence and phosphorescence respectively [51]. By investigating luminescence spectra and lifetimes it is possible to estimate decay constants including quenching, see figure $1.3[40,51]$.

Quenching is a process where the energy of an excited electron find alternative pathways than luminecense to relax to a lower state, for example collisional quenching, resonant energy transfer and Dexter interaction [51].

Gold nanoparticles can quench chromophores [51-54]. They can also increase radiative decay and rate of excitation $[51,54]$.

\subsection{Optical design}

By focusing the laser beam into the filter, a higher intensity and lower cut-off energy can be achieved $[7,21,24,31,40]$. Both the z-scan and OPL-measurements employ a focused laser beam (section 3.1.2 and 3.1.1). In this section methods to calculate the focus size and its impact on practical system design will be explained. 


\subsubsection{Laser focus size}

To reach a sufficiently high intensity/fluence, the laser beam is often focused into/on the filter $[7,21,24,31,40]$. A gaussian beam is often used for Z-scan measurements due to its theoretical simplicity [21]. Though alternative beam shapes can be handled numerically, and often necessary to contemplate due to imperfections in lasers $[31,55]$. The radius of a perfect gaussian beam focus, $\omega_{0}$, can be described by

$$
\frac{\omega_{0}}{\omega}=\frac{\frac{f \lambda}{\pi \omega^{2} n}}{\sqrt{1+\left(\frac{f \lambda}{\pi \omega^{2} n}\right)^{2}}}
$$

where $f$ is the focal length of the lens, $\omega$ the beam radius at the lens and $n$ the index of refraction in the medium [47]. Assuming that $\lambda \ll f / \omega$ and Taylor expanding around $\lambda=0$ we get the well known rule of thumb

$$
\omega_{0} \approx \frac{f \lambda}{\pi \omega n} .
$$

Any imperfections in beam quality will result in a larger spot size [31].

Another variant of a perfect beam is that of flat wave cut by a circular aperture with radius $a$ and focused into a spot at distance $f$, an Airy disk [56]. For realistic long-range laser protection applications, this beam geometry is expected [24]. Assuming that the spot size is much smaller than the focal length of the lens the Airy disk is described by,

$$
I(r)=I_{0}\left[\frac{2 J_{1}\left(\frac{2 \pi a r}{\lambda R}\right)}{\frac{2 \pi a r}{\lambda R}}\right]^{2}
$$

where $r$ is the distance from spot center and $J_{1}$ is a Bessel function of the first kind [56]. A comparison between a gaussian and airy disk spot is plotted in figure 1.4, where the functions have been multiplied by $2 \pi r$. It shows how even an ideal reverse saturable absorber (figure 1.1) will show a slope after the cut-off level has been reached due to the low fluence but large area rings not being caught by the filter. This problem has been known in the optical power limiting research field for a long time [57]. In astronomical telescopes, Airy rings can be removed by a technique known as apodization [58].

\subsubsection{Optical system design for optical power limiting}

While the nonlinear scattering is not expected to be sphericaly distributed [7, 46], the sperical approximation can be used to gain an understanding of an inherent limitation of nonlinear scatterers as self-activating filters. Since the filter is placed in an intermediary image plane, scattered light collected by following optics will still be imaged on the sensor. The same is true for non-linear absorbers with high fluorescence and/or phosphorescence efficiency. If the entrance pupil of the optics after the filter has the radius $r$ and a distance $R$ from the filter the fraction of scattered light transmitted is 


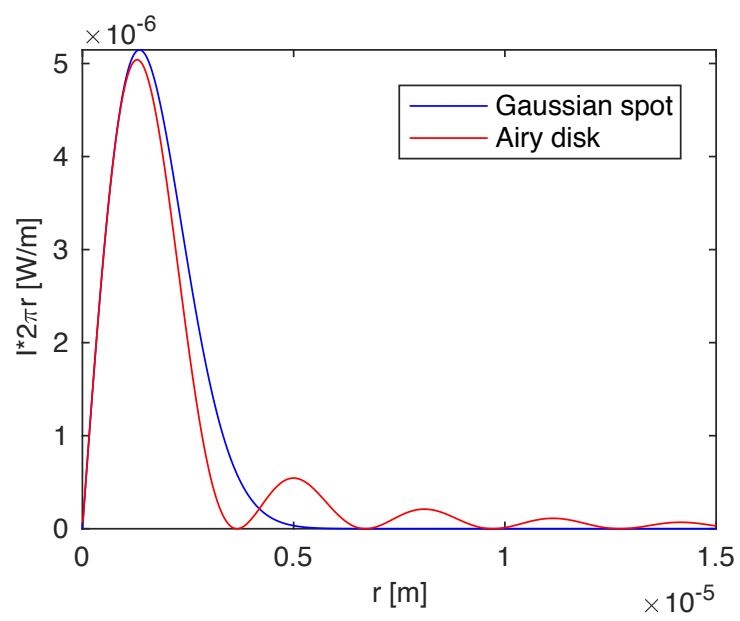

Figure 1.4. Comparison between Gaussian and Airy disk focus. The intensity at position $r$ from the center is multiplied by the circumference $2 \pi r$. The multiplication by $2 \pi r$ is done to show the impact of the large area of Airy rings. The beam radius of the gaussian beam at the lens is set to $a / \sqrt{2}$, where $a$ is the lens radius for the Airy disk. $f=0.1 \mathrm{~m}, \lambda=600 \mathrm{~nm}, a=1 \mathrm{~cm}, n=1$ and $I_{0}=1 \mathrm{~W} \mathrm{~m}^{-2}$.

$$
\sigma \eta \frac{r^{2}}{4 R^{2}}
$$

where $\sigma$ is the fraction of light scattered and $\eta$ a factor (possibly more than 1 ) representing deviations from spherical scattering [16]. The difficulty of removing scattered light from the beam-path has been known in the research field [34]. This means that to achieve an optical density of OD4 for a half inch diameter lens after a non-linear scatterer, a $30 \mathrm{~cm}$ focal length would be necessary. This would in most cases put unacceptable design constraints on the optical system as a whole.

\subsection{Chromophores for optical power limiting}

There exist several classes of materials for OPL, e.g. metal nanoparticles, carbon based materials, organic molecules and hybrid organic-inorganic molecules [21]. In this work the experiments were focused on investigating ways to improve the performance of organometallic dyes.

Metal organic complexes are appreciated for the ability to combine the advantages of organic and inorganic materials for optical power limiting [21]. Strengths include strong non-linear response, fast response times and large design flexibility [21]. More specifically metal acetylides are known for large nonlinear optical properties while retaining good transparency in the visible wavelength region [21].

In organometallic complexes OPL performance is often achived by combining several optically nonlinear processes, i.e. 2PA in combination with RSA [21, 59, 
60]. To increase the intersystem crossing (ISC) rate into a highly absorbing triplet state, a heavy metal atom such as Platinum is often used [21, 59, 60].

The first section gives an overview of Pt(II)-acetylides and especially PE2 and PE3. The second section gives an overview of fluorene based OPL chromophores.

\subsubsection{Pt(II)-acetylides}

Platinum(II) acetylides are a class of organometallic complexes used for optical power limiting [21]. Platinum acetylides are also known as platinum phenylethynyls and Pt:ethynyl complexes [10, 11, 14, 21].

Platinum acetylides are known as very good broadband optical power limiters in the visible wavelength range. [10, 11, 21]. The Platinum center in combination with the ligands' electron transporting acetylide groups cause ISC due to its weakly bound electrons, while the ligands contribute to two-photon absorption [10, 61]. The platinum acetylides are characterized by fast inter system crossing times, high excited state absorption (ESA), good two-photon absorption and long triplet lifetimes $[10,59]$. The singlet absorption peak is often in the $\mathrm{UV} /$ deep blue range while the triplet absorption cover a wide wavelength range [14, 59, 61-65]. The low ground state absorption versus excited state absorption of platinum acetylenes in the visible make them excellent reverse saturable absorbers (section 1.3.3) [59]. For blue light the dominant mechanism is one-photon absorption into the singlet state with intersystem crossing into the highly absorbing triplet state [59, 62]. For green, a "forbidden" direct transition into the triplet state is important [59, 62 ]. While in the yellow/red region two-photon absorption followed by intersystem crossing dominates $[59,62]$.

The two platinum acetylides chromophores used to investigate co-doping with gold nanoparticles are based upon PE2 and PE3. These two chromophores show a strong triplet state absorption in the order of $10^{4}$ to $10^{5} \mathrm{M}^{-1} \mathrm{~cm}^{-1}$ in the visible while the singlet absorption peaks are in the UV [14]. The chromophores have been functionalized with $\mathrm{CH}_{2} \mathrm{OH}$ to facilitate dissolving into the matrix precursor [2].

\section{PE2}

The PE2 chromophore is a molecule well characterized in the literature. A comparison between PE2 and PE2- $\mathrm{CH}_{2} \mathrm{OH}$ is shown in figure 1.5. Due to their similarity, photophysical constants for PE2 is used in the population modelling work (chapter 2). The singlet absorption peak is located in the UV, with a large absorbance up to $9 \cdot 10^{4} \mathrm{M}^{-1} \mathrm{~cm}^{-1}$ at around $355 \mathrm{~nm}$ (in benzene solution) [14]. The triplet absorption peak is broadband and covers the visible range [14,62]. The absorbance varies between $1 \cdot 10^{4}$ and $4 \cdot 10^{4} \mathrm{M}^{-1} \mathrm{~cm}^{-1}$ for visible light [14]. The singlet absorption in the visible is low, around $6 \mathrm{M}^{-1} \mathrm{~cm}^{-1}$ at $450 \mathrm{~nm}$ and $0.2 \mathrm{M}^{-1} \mathrm{~cm}^{-1}$ at $600 \mathrm{~nm}$ [14]. There is a short inter-system crossing time of less than $300 \mathrm{ps}$ while the inter-system crossing quantum efficiency is high, at 0.92 [14, 62]. The phosphorescence decay time for PE2- $\mathrm{CH}_{2} \mathrm{OH}$ in MTEOS Sol-Gel glass is around 1-2 us [2]. At $595 \mathrm{~nm}$ there is a two-photon absorption peak of $290 \mathrm{GM}$ [11]. 


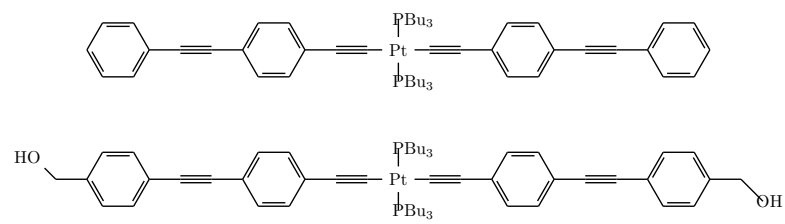

Figure 1.5. Comparison between PE2 (upper) and $\mathrm{PE} 2-\mathrm{CH}_{2} \mathrm{OH}$ (lower) [2, 14, 18]. $\mathrm{PBu}_{3}$ is tributylphosphine.

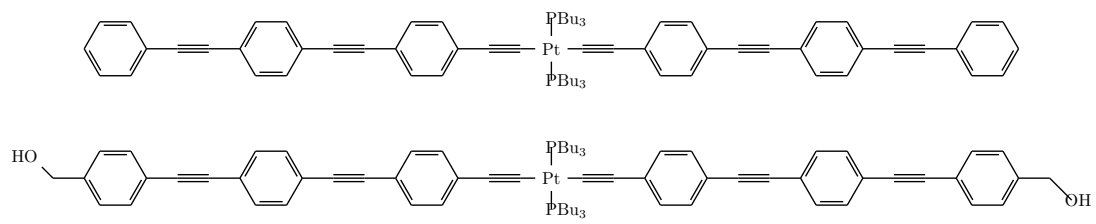

Figure 1.6. Comparison between $\mathrm{PE} 3$ (upper) and $\mathrm{PE} 3-\mathrm{CH}_{2} \mathrm{OH}$ (lower) [2, 14, 19]. $\mathrm{PBu}_{3}$ is tributylphosphine.

\section{PE3}

PE3 is like PE2 but with an extra phenyl-ethynyl group at the two phenyl-ethynyl ligands. A comparison between PE3 and $\mathrm{PE} 3-\mathrm{CH}_{2} \mathrm{OH}$ is shown in figure 1.6. As expected this extra phenyl-ethynyl group increases non-linear absorption performance [10]. A stronger, compared to PE2, two-photon absorption peak of around $680 \mathrm{GM}$ is located at $610 \mathrm{~nm}[10]$. The singlet absorption peak is somewhat redshifted to $377 \mathrm{~nm}$ [14]. The excited state absorption is significantly larger, especially in the red, up to $4 \cdot 10^{8} \mathrm{M}^{-1} \mathrm{~cm}^{-1}$ [14]. However, the inter-system crossing quantum efficiency is lower at 0.72 [14]. Still, the inter-system crossing time is shorter at around $20 \mathrm{ps}[10]$.

\subsubsection{Fluorenes}

Fluorene is an often used moiety in both organometallic and organic molecules, known for its high 2PA [21, 49, 61, 66-69]. Singlet ESA has also been reported for fluorenes $[49,50]$, e.g. 2,2'-(9,9-dihexyl) bifluorene with a for the singlet state ESA lifetime of $450 \mathrm{ps}$ and a $2 \mathrm{PA} / \mathrm{ESA}$ peak at around $540 \mathrm{~nm}$ [49]. The two hexyls on the fluorene moiety are included for better solubility [70], which is important if the molecules are to be incorporated into a Sol-Gel matrix [2].

In this work three multi-branched fluorene molecules with six 9,9-dihexyl fluorene groups each are investigated. By using multi-branched configurations, the 2PA of fluorene molecules has been improved [70, 71]. The difference between each molecule is in the central moiety. Molecule A has a benzene ring, see figure 1.7. Molecule B is build around a para-dibromobenzene unit, see figure 1.8. This moiety has been identified as an ISC promoter [72]. Finally Molecule C is constructed around a $\mathrm{Pt}(\mathrm{II})$-acetylide moiety, see figure 1.9 and section 1.5.1.

Molecule A was selected as a fully organic baseline, lacking an ISC promoter. Molecule B due to the electronegativity of Bromine in the ISC unit. The Pt(II)- 


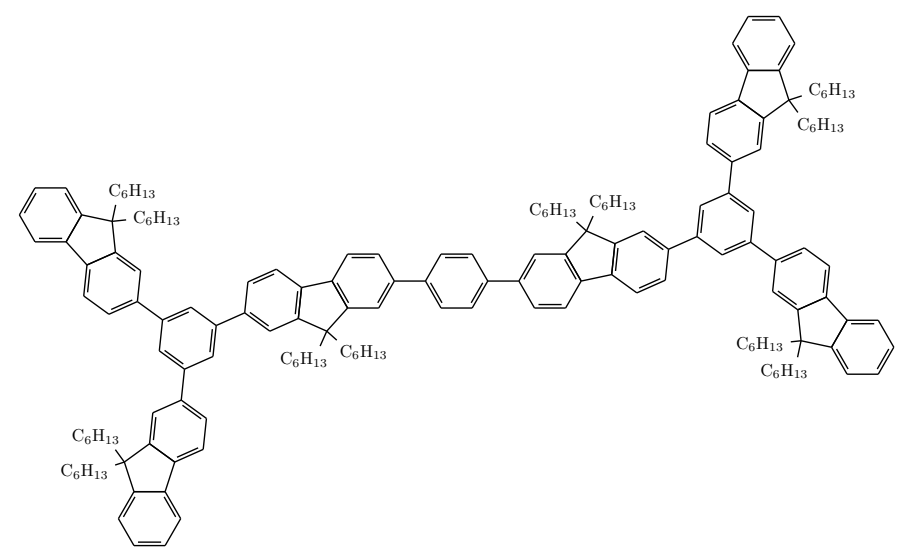

Figure 1.7. Molecule A.

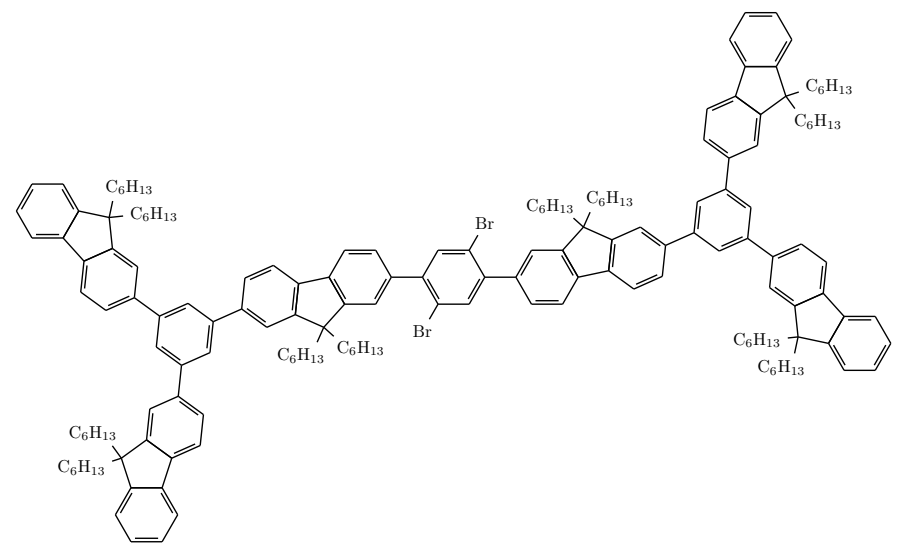

Figure 1.8. Molecule B.

acetylide in turn has been known to act as an electron donor, e.g. in PE3 [10]. A common pattern for designing 2PA chromophores is to separate an electron donor and/or acceptor by a $\pi$-conjugated moiety $[21,59,60]$.

\subsection{Sol-Gel glasses}

Dyes doped into solids instead of dissolved into solution has obvious advantages for practical applications [2]. Chromophore doping of glasses can be characterized into two classes, either Class 1 where the dye molecules are embedded in the glass matrix or Class 2 where the chromophores are covalently bound to the matrix [22].

A glass matrix widely used for nonlinear optical materials is PMMA, an organic glass (Commonly known as acrylic glass and is not a Sol-Gel.) [21, 22, 59]. It is 


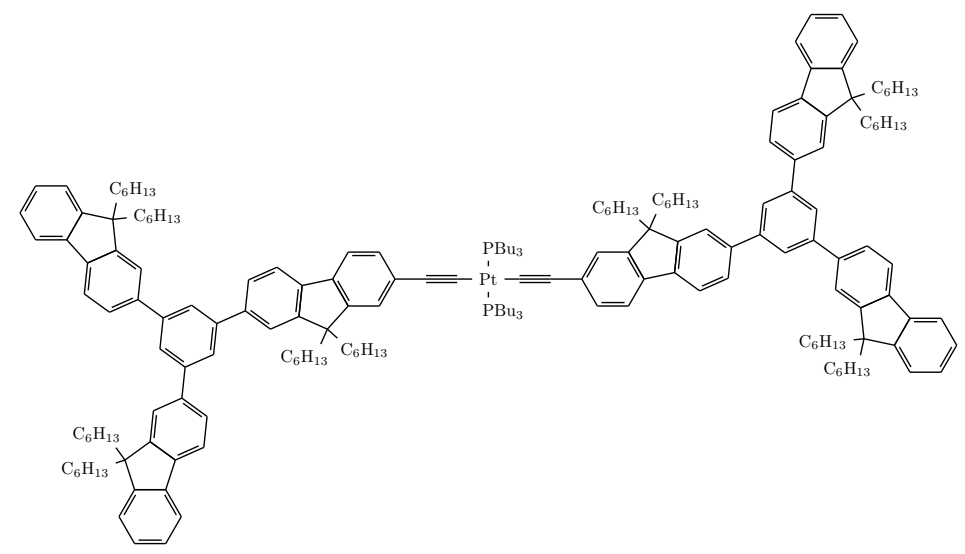

Figure 1.9. Molecule C.

known for its good mechanical properties [22, 59]. Bulk PMMA has been both Class 1 and 2 doped with high concentrations of PE2 derivatives [22].

Recent advances in Sol-Gel technology allow for the glasses to be made far more quickly, a problem that earlier has hindered their use in real applications $[2,59$, 73]. Compared to PMMA the Sol-Gel glasses have better optical quality, thermal stability and less susceptibility to damage [59]. Also, the process is at relatively low temperature, increasing the number of potential chromophores [2]. Both Class 1 and Class 2 doping is possible [2, 73]. Extremely high concentrations of up to $400 \mathrm{mM}$ of $\mathrm{PE} 2-\mathrm{CH}_{2} \mathrm{OH}$ has been achieved with Class 1 doping [2]. But the clamping level did not lower linearly with increasing chromophore concentration [2].

\subsubsection{Pores}

It is possible to control the pore size by modifying the matrix of the Sol-Gel glass [2]. This can be done by changing the precursor of the glass, such as MTEOS ${ }^{1}$ (methyltriethoxysilane) or VTEOS (vinyltriethoxysilane) [2]. Thereby controlling the amount of quenching of the triplet state from the formation of singlet oxygen [2]. Controlling the chromophore exposure to oxygen and thereby increasing the lifetime of its triplet state has been used to increase reverse saturable absorption of less intense light [48].

\subsection{Gold nanoparticles}

Gold nanoparticles are particles small enough that when light strikes them, the free electrons in the gold metal form resonances depending on the shape and size of the particle [74]. Modern methods such as the "discrete dipole approximation" are able to accurately model the absorption and scattering cross-sections of different shapes

\footnotetext{
${ }^{1}$ The glass samples used in this work were MTEOS glasses.
} 


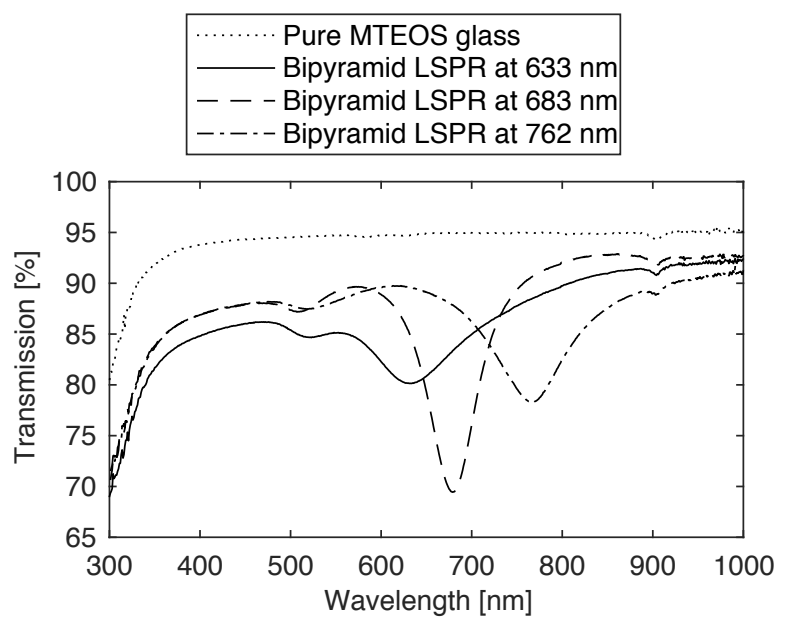

Figure 1.10. MTEOS glasses doped with different sizes/shapes of bipyramidal gold nanoparticles. The $\mathrm{Au}^{0}$ concentration is $0.125 \mathrm{mM}$. A glass without gold nanoparticles is included for comparison. Measured by Lopes [17].

and constellations of gold nanoparticles [74-76]. By controlling the shape of gold nanoparticles it is possible to choose where the plasmon resonance is located in the wavelength spectrum $[74,76,77]$. The change in plasmon resonance wavelength due to different sizes/shapes of bipyramidal gold nanoparticles is demonstrated in figure 1.10 [17]. Gold nanoparticles in close proximity to each other show a shift in plasmon resonance wavelength $[3,4,78,79]$.

\subsubsection{Enhancement of chromophores}

Gold nanoparticles can both enhance and quench the fluorescence of dyes [51-53, $74,80]$. At a few nanometers distance quenching is dominant while at around $10 \mathrm{~nm}$ field enhancement dominates [51, 74, 80]. Longer distance effects, such as increased radiative rate or chromophore to gold nanoparticle energy transfer due to overlapping fluorescence and plasmon resonances, have shown longer interaction ranges of several tens of nanometers [51, 81, 82].

Chromophore two-photon absorption enhancement by gold nanoparticles has been reported from multiple sources [59, 62]. Two-photon absorption depend on the fourth power of the electric field enhancement around a gold nanoparticle [83]. Surrounding a spherical nanoparticle the intensity enhancement $\left(\sim|E|^{2}\right)$ field can be described by Tanabe's analythical model

$$
\eta=\left|1+2 \frac{a^{3}}{r^{3}} \frac{\epsilon_{1}-\epsilon_{m}}{\epsilon_{1}+2 \epsilon_{m}}\right|^{2} \cos ^{2} \theta+\left|-1+\frac{a^{3}}{r^{3}} \frac{\epsilon_{1}-\epsilon_{m}}{\epsilon_{1}+2 \epsilon_{m}}\right|^{2} \sin ^{2} \theta
$$

where $a$ is the nanoparticle radius, $r$ the distance from the nanoparticle center to the observing point, $\epsilon_{1}$ is the dielectric constant of the surrounding medium, 
$\epsilon_{m}$ the dielectric constant of the nanoparticle and $\theta$ the angle between the electric field and the vector between the particle position and observing point [12]. This model was used to feed the 2PA field enhancement model in chapter 4 . 


\section{CHAPTER 2}

\section{Population models}

In this chapter numerical population models are described in a more verbose manner than was possible in the tutorial article [16]. Population modelling is widely used to model the photophysical dynamics of chromophores $[10,11,13,31,40$, 84]. The technique can basically be described as a numerical implementation of a Jablonsky diagram (figure 1.3), evolved stepwise with increments of $\Delta t$.

Numerical population models have been coupled to beam propagation models [31, 85-87], but in this work a point model is used. Initially, it was used to qualitatively test the hypothesis of $2 \mathrm{PA}$ field enhancement being the cause of OPL enhancement at $600 \mathrm{~nm}$ for $\mathrm{PE} 2-\mathrm{CH}_{2} \mathrm{OH}[18,19]$. In the tutorial article it was further developed to investigate the impact on OPL performance of varying different photophysical parameters [16]. It is also possible to use a point model to check the validity of $2 \mathrm{PA}$ measurements by the Z-scan method [10].

To facilitate fast iteration when evaluating different hypotheses, implementing a numerical population model in a matrix formalism is helpful. If $\Delta t$ is short enough a single time step of a population model can be implemented by

$$
\begin{aligned}
d N_{i}^{+} & =\sum_{j} \sigma_{j i} J \Delta t N_{j}+\sum_{j} \omega_{j i} J^{2} \Delta t N_{j}+\sum_{j} \frac{\Delta t}{\tau_{j i}} N_{j} \\
d N_{i}^{-} & =\sum_{j} \sigma_{i j} J \Delta t N_{i}+\sum_{j} \omega_{i j} J^{2} \Delta t N_{i}+\sum_{j} \frac{\Delta t}{\tau_{i j}} N_{i} \\
d N_{i} & =d N_{i}^{+}-d N_{i}^{-}
\end{aligned}
$$

where $N_{i}$ is the population density of state $i$ in $\left[\mathrm{cm}^{-3}\right], d N_{i}^{+}$and $d N_{i}^{-}$the change in population density from electrons entering and leaving state $i, J$ the photon flux density in $\left[/ \mathrm{cm}^{2} \mathrm{~s}\right], \sigma_{i j}$ the single photon cross section for electrons 
in state $i$ being excited into state $j$ expressed in $\left[\mathrm{cm}^{2}\right], \omega_{i j}$ the two-photon cross section in $\left[\mathrm{cm}^{4} \mathrm{~s}\right]$ and $\tau_{i j}$ the relaxation time into orbital $j$ expressed in $[\mathrm{s}]$. Care must be taken to avoid using too long time steps, $\Delta t$, compared to photon flux density and relaxation times. The attenuation coefficient $\alpha$ in $[/ \mathrm{cm}]$ can then be calculated by

$$
\alpha=\sum_{i} \sum_{j}\left(\sigma_{i j} N_{i}+\omega_{i j} J N_{i}\right)
$$

A simplified version of the five-level Jablonsky diagram shown in figure 1.3 can be implemented by a set of $3 \times 3$ matrices. The inherent assumptions are:

1. The five-level model is relevant, meaning that the contribution from higher singlet and triplet levels can be approximated by $\mathrm{S}_{2}$ and $\mathrm{T}_{2}$.

2. The $\mathrm{S}_{2}$ and $\mathrm{T}_{2}$ states are quickly depopulated.

3. No RSA or saturable absorption in occurs the singlet state. For continous wave models (steady state), this can cause an OPL depression at intermediary fluence levels [88]. It can easily be remedied by adding a $\sigma_{22}=\sigma_{S 2}$ entry, if singlet ESA has been measured.

4. The ISC-time is short enough to depopulate the $\mathrm{S}_{1}$ state before a significant population build-up. If an upper level is well populated, stimulated emission needs to be considered [88]. This can be modelled by making the absorption cross-section matrix antisymmetric, i. e. $\sigma_{i j}=-\sigma_{j i}$ when $i \neq j$.

The wavelength dependent linear absorption cross-section is described by

$$
\sigma_{i j}(\lambda)=\left[\begin{array}{ccc}
0 & \sigma_{S} & \sigma_{F} \\
0 & 0 & 0 \\
0 & 0 & \sigma_{T}
\end{array}\right]
$$

where $\sigma_{S}$ is the linear absorption cross section of the $\mathrm{S}_{0}$ to $\mathrm{S}_{1}$ state, $\sigma_{F}$ is the forbidden $\mathrm{S}_{0}$ to $\mathrm{T}_{1}$ transition and $\sigma_{T}$ triplet ESA cross-section. If needed singlet 2PA can be included by

$$
\omega_{i j}(\lambda)=\left[\begin{array}{ccc}
0 & \omega_{S} & 0 \\
0 & 0 & 0 \\
0 & 0 & 0
\end{array}\right]
$$

The lifetimes are represented by

$$
\tau_{i j}(\lambda)=\left[\begin{array}{ccc}
\infty & \infty & \infty \\
\tau_{S} & \infty & \tau_{i s c} \\
\tau_{T} & \infty & \infty
\end{array}\right]
$$

where $\tau_{T}$ is the triplet lifetime and $\tau_{i s c}$ the ISC-time. To model ISC quantum efficiency $\Phi_{I S C}, \tau_{S}$ was added to depopulate the $\mathrm{S}_{1}$ state 


$$
\tau_{S}=\tau_{I S C} \frac{\Phi_{I S C}}{1-\Phi_{I S C}}
$$

[17]. To visualize the impact on OPL performance by changing a specific photophysical parameter, the time-resolved attenuation coefficient improvement function can be used

$$
\gamma(t)=\frac{\alpha(t)}{\alpha_{r e f}(t)}
$$

were $\alpha_{r e f}(t)$ is the unchanged attenuation coefficient at time $t$ and $\alpha(t)$ has had one or more photophysical parameters changed. This attenuation coefficient will be used in chapter 4 to build a qualitative model of $2 \mathrm{PA}$ field enhancement, see figure 4.3 .

\subsubsection{Conversion of units}

To aid in the implementation of population modelling software, unit conversion formulas from more widely used units are included here. Numerical density is often expressed in molar concentration, $N_{M}$, in $\left[\mathrm{mol} \mathrm{L}^{-1}\right]$, the starting numerical density can then be expressed by

$$
N_{0}=N_{M} \cdot n_{0} / 1000
$$

where $n_{0}$ is the Avagadro constant. The photon flux depends on both the irradiance, $I\left[\mathrm{~W} \mathrm{~cm}^{-2}\right]$, and wavelength, $\lambda[\mathrm{m}]$,

$$
J=\frac{I \lambda}{h \cdot c}
$$

where $h[\mathrm{~J} \mathrm{~s}]$ is the Plank constant and $c\left[\mathrm{~m} \mathrm{~s}^{-1}\right]$ the speed of light [56].The two-photon cross-section can be converted from [GM] (Göppert-Mayer units) by

$$
\omega_{j i}=\omega_{G M} \cdot 10^{-50}
$$

[11]. The linear cross section, $\sigma_{j i}$, is often expressed in absorbance, $A$ [/Mcm], as

$$
\sigma_{j i}=1000 \ln 10 \cdot A / n_{0}
$$

(Observe the change in base!) 


\section{CHAPTER 3}

\section{Characterization of OPL materials}

This chapter is based on the experimental part of article 4, explaining how to evaluate and characterize Optical Power Limiting (OPL) materials with a focus on Reverse Saturable Absorber (RSA) molecules [16]. Also, a $1200 \mathrm{~nm}$ to $1550 \mathrm{~nm}$ $\mathrm{f} / 5$-setup is briefly described. A method to evaluate OPL materials is to directly measure the sample's ability to attenuate radiation, see section 3.1. But to understand the cause of the OPL performance of a material, its photokinetics needs to be understood. To set the population model parameters described in chapter 2 correctly, several photophysical measurements described in section 3.2 are necessary.

\subsection{Optical Power Limiting Measurements}

Two of the most often used measurement techniques for measuring OPL performance are the intensity scan (section 3.1.1) and the Z-scan (section 3.1.2). For a wider review of optical power limiting measurement techniques, see Dini et. al's review [21].

\subsubsection{Intensity scanning a.k.a. OPL measurement}

A straightforward measurement method often used is placing the laser focus in the sample and varying the incoming irradiance or fluence [21]. Recording both the incoming pulse fluences and outgoing pulse energies, example data as shown in figure 3.1 can be collected. The x-axis was for this data chosen to presented as fluence $\left[\mathrm{J} \mathrm{cm}^{-2}\right]$ since the RSA response depends on fluence instead of intensity [7]. The $y$-axis was presented in pulse energy $[\mu \mathrm{J}]$ because it is more easily related to sensor damage thresholds and dynamic range. 


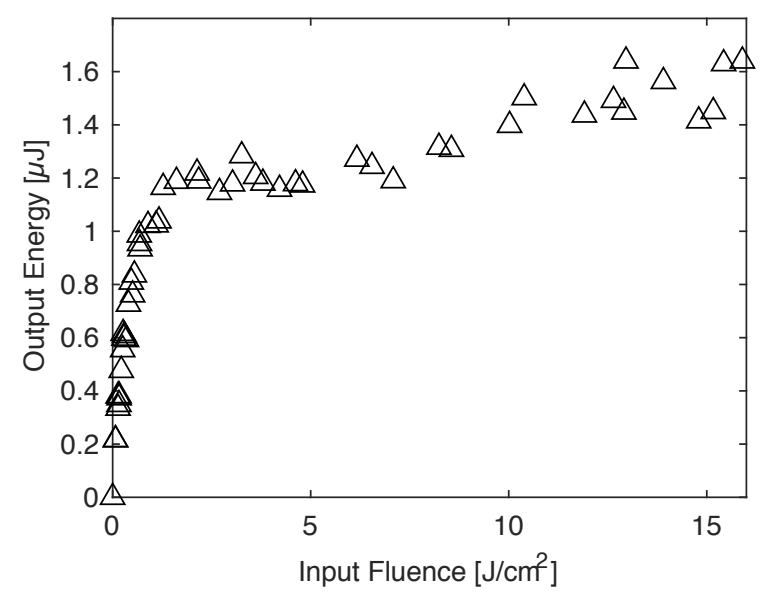

Figure 3.1. OPL measurement of $50 \mathrm{mM} \mathrm{PE} 3-\mathrm{CH}_{2} \mathrm{OH}$ in MTEOS glass [19].

The $\mathrm{f} / 5$ setup is widely used to perform intensity scan measurements $[24,31$, 89-92]. An f/5 system is selected due to its similarity to real-world systems [24, 34]. A widely used f/5 design, first published by Vincent et. al [92] can be described as:

1. A top-hat collimated beam of $2 \mathrm{~cm}$ diameter and known pulse energy enters a $\mathrm{f}=10 \mathrm{~cm}$ lens.

2. The sample is placed at the focus. The beam waist diameter is known from knife-edge measurements. A camera can be used to check beam alignment.

3. After the focus an $\mathrm{f}=4 \mathrm{~cm}$ lens is placed, creating a $2.5 \mathrm{x}$ telescope.

4. An $8 \mathrm{~mm}$ aperture cuts the edge of the collimated beam. The aperture after the $\mathrm{f} / 5$ telescope is inserted to simulate the human iris [24].

5. An $\mathrm{f}=1 \mathrm{~m}$ lens focuses the beam upon a small aperture. This aperture size varies between setups. It is used to stop light scattered by the sample at high pulse energies [89]. For glass samples this aperture can be removed, see article 1-3.

6. The remaining pulse energy is measured by a pulse energy detector.

For an example f/5 setup, see section 3.1.1 and figure 3.2.

The pulse energies for the intensity scan has, by nature of the measurement, to be larger than for the z-scan. It is therefore standard procedure to move a solid sample between each shot or keep the pulse-rate low for a liquid, e.g. [2, 93]. Due to the risk of measuring OPL deriving from damage (which would be bad for 
practical filters), a definition of damage is needed. A definition often used is the onset of a sudden decrease in transmittance from a single pulse. An alternative more stringent definition of no damage is not finding any increase in attenuation for several pulses while finding no damage by microscope [94].

A drawback with the intensity scan is that it can not differentiate the origin of the OPL, i.e. non-linear absorption or refraction [21]. In article 1 an integrating sphere is used to catch the non-linearly scattered light, thereby cancelling the OPL effect and giving answer to its origin [17].

When doing measurements with an $\mathrm{f} / 5$ setup, its important to consider its sensitivity to alignments errors. If comparisons across measurements from different calibrations are to be made, a reference sample is necessary.

\section{0-1550 $\mathrm{nm}$ setup}

Based on the f/5-setup for visible light [92], an OPL characterization setup for the $1200 \mathrm{~nm}$ to $1550 \mathrm{~nm}$ wavelength region was designed. As a by-product of the alignment procedure, the set-up was optimized for wavelength scanning measurements. This was necessary due to the scarcity of alignment tools, such as cameras with phosphorescent layers, outside of the fiber-communication wavelength bands. The beam path can be described as (see figure 3.2):

1. An Nd:YAG laser with an OPO gives wavelength tunable nanosecond pulses in the infra-red region.

2. A distant $7 \mathrm{~mm}$ aperture functions as an alignment aid and beam clean-up. ${ }^{1}$

3. A 3x Keplerian telescope is used to expand the beam. A Keplerian telescope is used due to scarce availability of concave achromatic lenses is this wavelength region. Achromatic lenses are not only necessary to allow for wavelength tuning with minimal realignment of the system, but allows for a smaller focus compared to simple spherical lenses.

4. Filter wheels attenuate the laser pulses in approximately OD 0.1 decrements.

5. A pinhole filter with $25 \mu \mathrm{m}$ diameter is placed between two $\mathrm{f}=20 \mathrm{~cm}$ lenses. The diameter is larger than the diffraction limit due to laser damage on the pinhole at larger fluences.

6. An iris aperture is used to aid in alignment. During measurement and calibration it is open.

7. A pellicle beam splitter sends a small part of the pulse energy to the reference detector. Due to the diffractive nature of the beam splitter, the percentage will vary with wavelength and the exact placement of the membrane.

8. A second open iris aperture is used for alignment.

9. A 2.66x Keplerian telescope expands the laser beam into a large diameter.

\footnotetext{
${ }^{1}$ Thanks to J. E. Slagle for teaching me this design trick.
} 


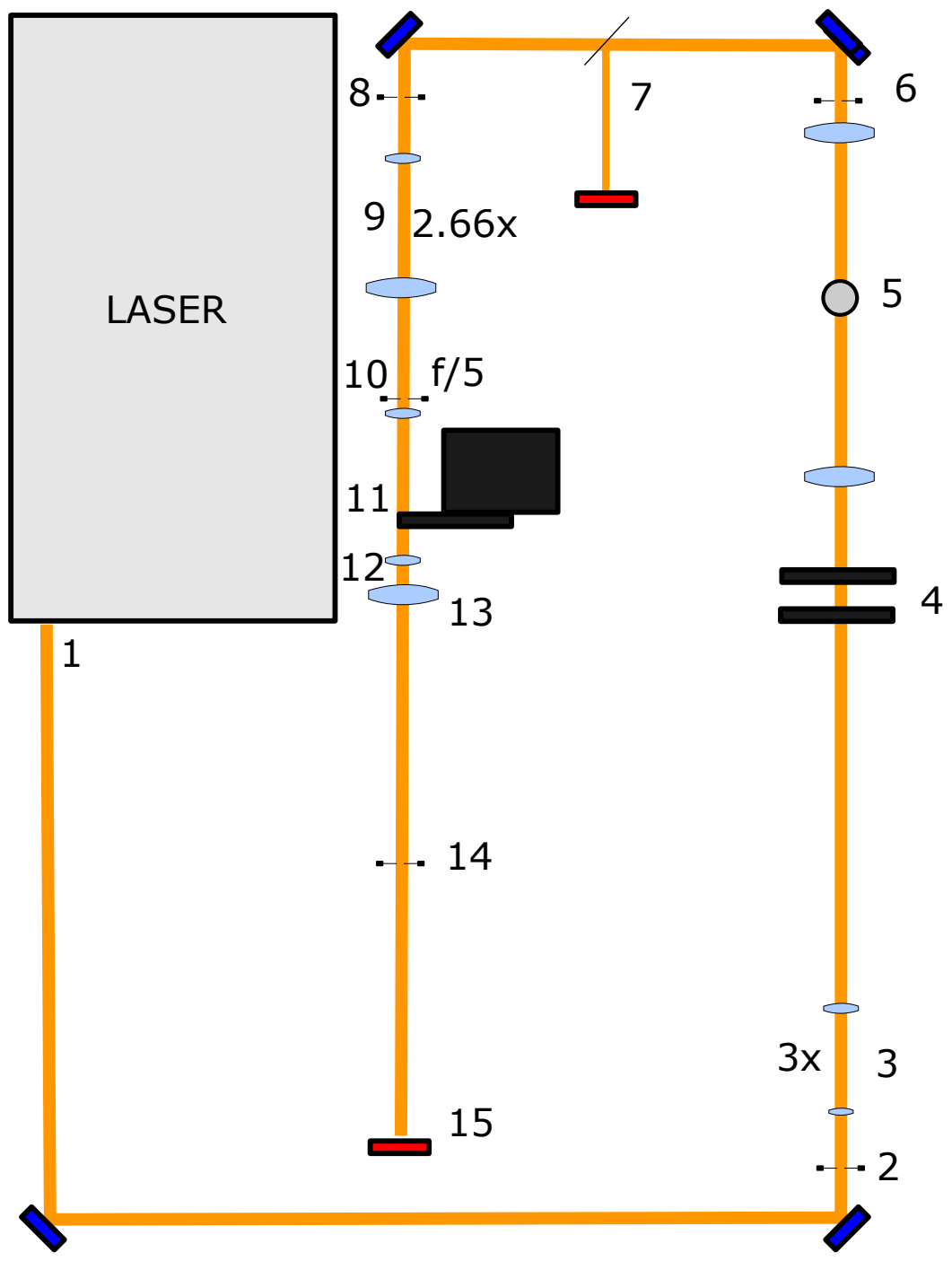

Figure 3.2. Schematic view of the f/5-setup for IR OPL measurements. Not to scale. 
10. A $2 \mathrm{~cm}$ aperture creates an approximately top-hat beam.

11. A $2.5 \times$ Keplerian telescope forms the $\mathrm{f} / 5$ system. In the telescope intermediary focus, the sample is placed on a motorized sample holder. It is also used to do $10-90 \%$ knife-edge measurements of the beam diameter.

12. Compared to a visible wavelength range, the $8 \mathrm{~mm}$ aperture after the $\mathrm{f} / 5$ system (the $2.5 \mathrm{x}$ Keplerian telescope) was not included. Its omission was necessary due to risk of error in calibration due to the invisible IR radiation. The omission makes the system less sensitive to non-linear refraction.

13. A simple plano-spherical lens of focal length $1 \mathrm{~m}$ is used to focus the light...

14. A small aperture is used to help in the alignment of the system during a wavelength scan. Due to some remaining chromatic aberrations, the front lens of the $\mathrm{f} / 5$ system has to be transposed. The system is well aligned when only a negligible fraction of the radiation is stopped by the closed aperture.

15. The signal pulse energy detector is placed $0.5 \mathrm{~m}$ after the aperture to avoid damaging the sensor surface.

The optical system is aligned at $1550 \mathrm{~nm}$ with the help of the apertures and a digital video camera with a phosphorescent layer. For other wavelengths the $1550 \mathrm{~nm}$ alignment is used while transposing the front lens of the $\mathrm{f} / 5$ telescope to maximize the transmission through the last aperture. As with the standard $\mathrm{f} / 5$ setup, the detectors are calibrated by linear fits from measuring without a sample with the signal detector at both its ordinary position and near the intermediary focus in the $\mathrm{f} / 5$ telescope. When changing wavelength, it is important to change the depth position of the sample in an iterative manner to keep the focus in the middle of the solution/glass material.

\subsubsection{Z-scan measurements}

In the optical power limiting field the z-scan measurement is an often used method to characterize OPL materials [7, 21]. The method allows for quantitative measurements of nonlinear absorption and refraction [7, 21, 37]. However, nonlinear absorption and scattering can not be distinguished by a z-scan [7].

The measurements are performed by transposing the sample along the beam path through the focus, see figure $3.3[7,21,37]$. When the filter is closer to the laser focus the intensity gets larger. By measuring both with and without the aperture, absorption and refraction can be distinguished [7, 21, 37].

The measured data is fitted to a model assuming that the nonlinear refraction and absorption can be described by

$$
\begin{aligned}
& n(I)=n_{0}+\gamma I \\
& \alpha(I)=\alpha_{0}+\beta I
\end{aligned}
$$




\section{Closed aperture:}

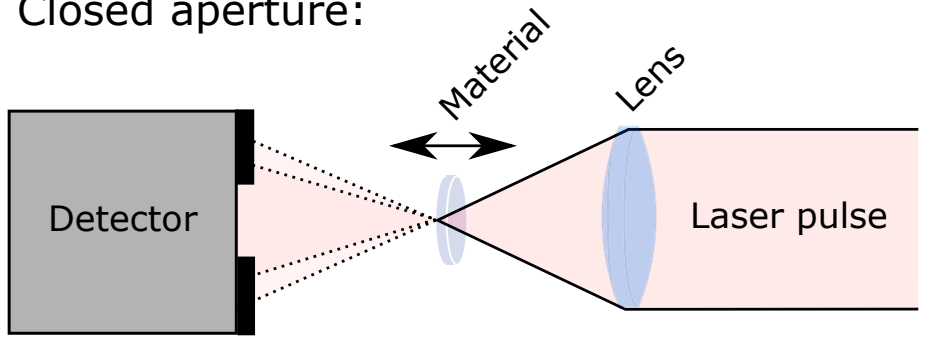

\section{Open aperture:}

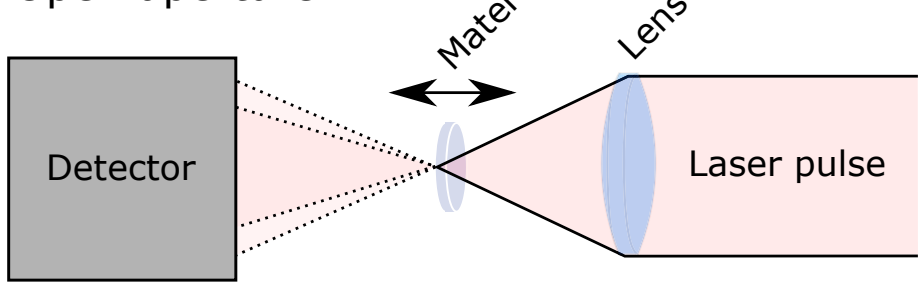

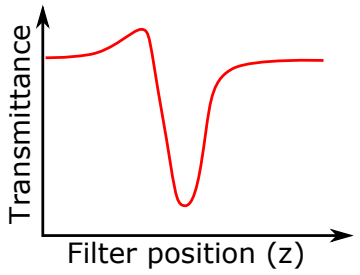

(a)

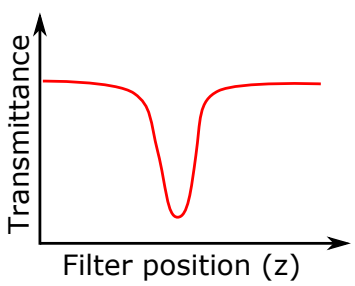

(b)

Figure 3.3. A z-scan measurement setup [37]. Reproduced with permission [16]. By measuring with both a closed and open aperture, non-linear absorption and refraction can be separated.

and thereby estimating the $\gamma$ and $\beta$ parameters [37]. By using a picosecond laser it is possible to decrease the influence of the triplet state (section 1.3.3) [7]. It is also possible to approximate the behaviour of reverse saturable absorption by a $\beta$ parameter [21].

While the original z-scan method assumes a gaussian beam and thin sample, more recent improvements to the z-scan method allows for non-gaussian beams and thick samples $[21,31,55]$. It is possible to apply this formalism for fluence, $F$ $\left[\mathrm{J} \mathrm{cm}^{-2}\right]$, instead of irradiance, $I\left[\mathrm{~W} \mathrm{~cm}^{-2}\right]$ [31]. Though the validity for nanosecond pulses is questionable [31].

\section{Two-photon absorption}

Equation 3.1b and 1.1a from the z-scan formalism have the same form. Open aperture z-scan method has often been used to determine $\beta$, the nonlinear twophoton absorption (2PA) coefficient [21, 40]. However, care must be taken with pulse length and repetition rate to avoid the influence of reverse saturable absorption $[10,11,31]$. 


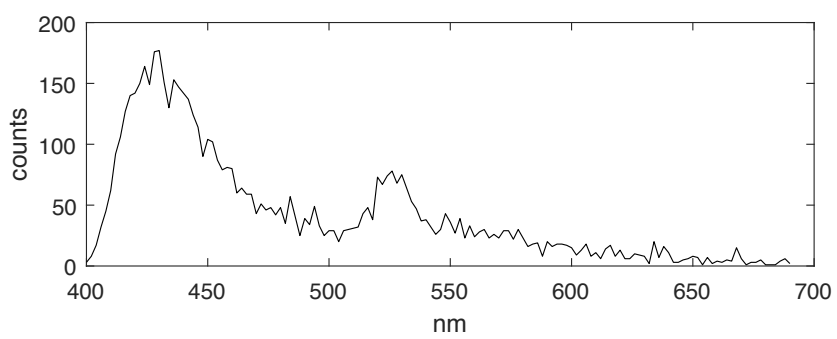

Figure 3.4. Luminescence spectrum of a $50 \mathrm{mM} P E 2-\mathrm{CH}_{2} \mathrm{OH}$ in MTEOS Sol-Gel glass.

\subsection{Photophysical measurements}

This section is based on article 4 and previous results by Glimsdal et al. [16, 40, 95, 96]. The focus is on what measurements are available and why they are necessary. For technical details, see article 4 and Glimsdal's PhD thesis [16, 40].

The photophysical measurements are often performed on solutions in an effort to gain an understanding of the general spectral properties and photokinetics of the molecule before incorporating it into a glass matrix [16].

\subsubsection{Linear absorption}

The linear absorption shows were the absorption bands are and shows the linear absorption in the wavelength range of OPL. Finding chromophores with high OPL but low linear absorption is important for creating OPL materials [97]. By also knowing the numerical concentration and refractive index the ground state linear absorption cross-section needed by population models can be deduced. Ellipsometry can be used to gain an understanding of more complex anisotropic media [41], e.g. [17].

\subsubsection{Luminescence}

Considering the importance of the decay constants for reverse saturable absorption (section 1.3.3), the luminescence properties of the filters characterized in this work needed to be investigated.

Luminescence spectra can tell information about the transition energy levels etc. These are of importance for materials employing Förster Resonant Energy Transfer (FRET) between donor and acceptor chromophores [48, 51]. The spectra are also necessary to interpret time-resolved luminescence measurements. An example luminescence spectra is given in figure 3.4, where the fluorescence peak is at $430 \mathrm{~nm}$ while the phosphorescence peak is at $526 \mathrm{~nm}$.

The time-resolved luminescence decay can be measured by time correlated single-photon counting (TC-SPC) for decay-times from around $50 \mathrm{ps}$ to around 1 us [16, 63]. For decays of long-lived phosphorescence, multichannel scaling (MCS) can be used instead $[16,98]$. Example TC-SPC data of phosphorescence is shown 


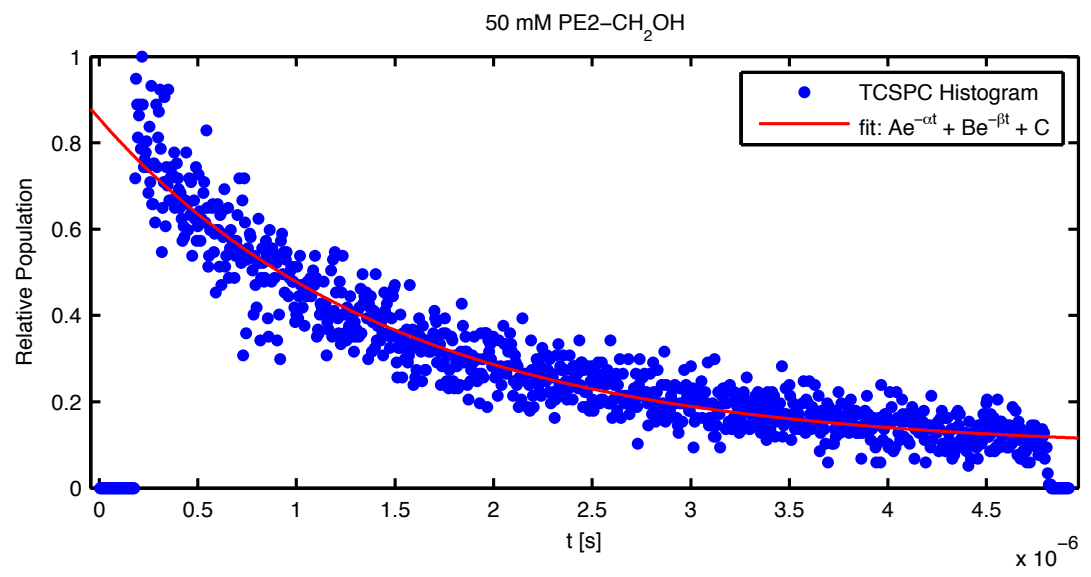

Figure 3.5. TCSPC measurement of the phosphorescence decay of a $50 \mathrm{mM}$ PE2$\mathrm{CH}_{2} \mathrm{OH}$ in MTEOS Sol-Gel glass.

in figure 3.5. It has been fit to a two-exponential decay model, often used to investigate the dynamics of chromophores [51].

\section{Quantum efficiency and two photon absorption}

If the luminescence spectrally overlaps with a reference sample's luminescence it is possible to measure the luminescence quantum efficiency $(Q E)$ of the sample $($ sam $)$ relative to the reference $($ ref $)$ by

$$
\frac{Q E_{\text {sam }}}{Q E_{\text {ref }}}=\frac{\text { Slope }_{\text {sam }}}{\text { Slope }_{\text {ref }}} \cdot \frac{n_{\text {sam }}^{2}}{n_{\text {ref }}^{2}}
$$

where Slope is measured by linear fitting the integrated luminescence to pulse energy and $n$ is the refractive index of the solution $[16,99]$. If also the 2PA crosssection of the reference is known, it is possible by a similar method to find the sample 2PA cross-section by

$$
\frac{L_{\text {sam }}}{L_{\text {ref }}}=\gamma \frac{Q E_{\text {sam }} \sigma_{\text {sam }}^{(2)} n_{\text {sam }}}{Q E_{r e f} \sigma_{r e f}^{(2)} n_{r e f}}
$$

where $L$ is the integrated luminescence, $\sigma^{(2)}$ is the $2 \mathrm{PA}$ cross-section and $\gamma$ differs from 1 if the collection coefficient, pulse profile or concentration differs between sample and reference $[16,100]$. If a suitable reference and sufficient luminescence is available the luminescence method of $2 \mathrm{PA}$ cross-section measurement is more sensitive than the z-scan [16]. 

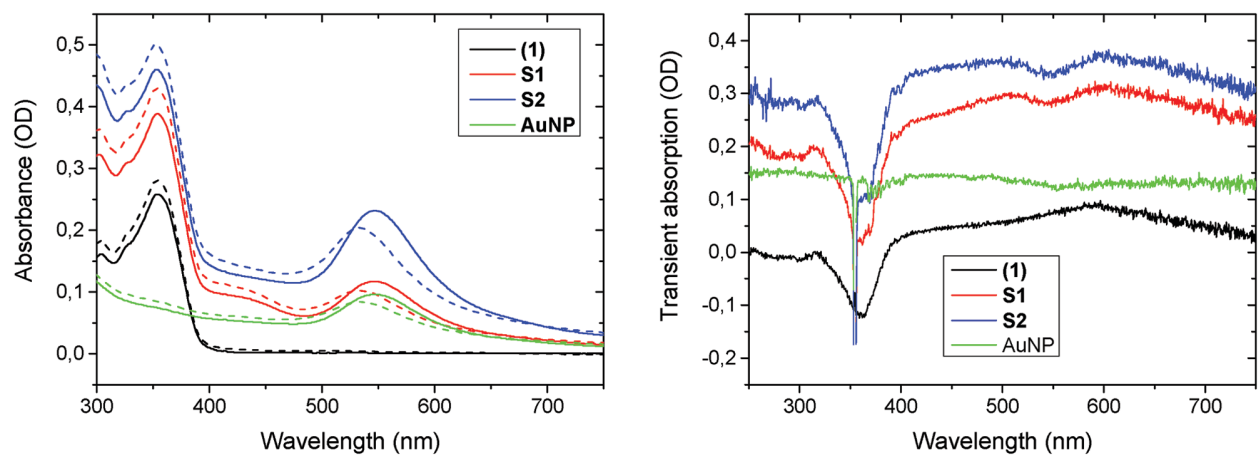

Figure 3.6. The left plot is the ground state absorption of $\mathrm{PE} 2-\mathrm{CH}_{2} \mathrm{OH}$ in THF (1), with varying amounts of $45 \mathrm{~nm}$ diameter spherical gold nanoparticles S1 \& S2 and only gold nanoparticles in THF AuNP. The dashed lines show the result of bleaching. The right plot shows the transient absorption. Excitation was from single $5 \mathrm{~ns}, 355 \mathrm{~nm}$ laser pulses. Both plots reproduced with permission, measured by Lindgren [18].

\subsubsection{Microsecond transient absorption}

For RSA chromophores the ESA spectra of a long-lived triplet state can be measured by a pump/probe setup [16, 96]. Flash photolysis used for excited state absorption measurements was pioneered by Porter in 1950 [40, 101]. In such a system, the pump flash-lamp or laser excites the sample. Through ISC a portion of the chromophores enters the triplet state. After a varying delay the probe flashlamp is fired and the spectrum of the transmitted radiation is recorded at different time steps. Such a system can measure ESA spectra with a lifetime in the $0.1 \mu \mathrm{s}$ to 100 us range [16].

Example data is given in figure 3.6. Transient absorption is the excited state absorbance subtracted by the ground state absorbance. By comparing the bleaching in the UV to the linear absorption, it is possible to estimate the fraction of molecules in the triplet state and thereby the ESA cross-section needed by population models [40].

\subsubsection{Ultra-fast transient absorption}

While the flash-lamp based transient absorption measurements can catch a longlived triplet ESA spectrum, alternative techniques are necessary to measure faster processes. Ultra-fast transient absorption can for example be used to find the ISC time [102] or explore singlet and triplet manifolds [103]. In these kind of measurements the pump is a picosecond or femtosecond laser. The probe beam is split from the pump beam and take a detour by a variable delay line. The probe beam is used to generate white continuum light, e.g. by a sapphire plate [20]. A time-resolved transient absorption spectrum can then be recorded.

This data is often fitted to standard decay and grow-in model generically de- 
scribed by

$$
O D(\lambda, t)=\sum_{i} c_{i}(\lambda) \exp \left(-t / \tau_{i}\right)+d(\lambda)
$$

where $\lambda$ is the wavelength, $t$ the time, $c_{i}(\lambda)$ the spectral basis vectors, $\tau_{i}$ the accompanying decay-times and $d(\lambda)$ a combination of the constant part of grow-ins and decays to slow to resolve from the available data. 
CHAPTER 4

\section{Gold nanoparticle glasses}

The first three articles of this work are highly interconnected [17-19]. Not only were the OPL measurements performed at the same occasion, but the analysis was done taking the results from all three articles into account (section 4.2).

\subsection{Summary of the results}

The first article reported on a wide variety of different shapes and concentrations of gold nanoparticles doped in MTEOS glasses. The second article investigated glasses doped as in the earlier article together with $50 \mathrm{mM} \mathrm{PE2}-\mathrm{CH}_{2} \mathrm{OH}$. The third article was about a more limited set of glasses doped with gold nanoparticles and $50 \mathrm{mM}$ PE3- $\mathrm{CH}_{2} \mathrm{OH}$. The different shapes and concentrations of gold nanoparticles are compiled in table 4.1. For more in-depth information about the samples, see the supplementary information of the articles [17-19].

\subsubsection{Glasses with only gold nanoparticles}

The MTEOS glasses doped with gold nanoparticles showed good optical power limiting performance for $532 \mathrm{~nm}$ pulses, but none at all for $600 \mathrm{~nm}$ pulses at the tested fluences [17]. At $532 \mathrm{~nm}$ the optical power limiting was better than for glasses doped with both chromophores and gold nanoparticles. The optical power limiting at $532 \mathrm{~nm}$ was absent when collecting the nonlinearly scattered light by an integrating sphere [17]. The linear transmittance spectra showed well defined plasmon peaks that did not show any marked widening or shift with increased gold nanoparticle concentration. 
Table 4.1. The different series of gold nanoparticle doping used in article 1 (only gold nanoparticles in MTEOS glass), article 2 (also doped with $50 \mathrm{mM} \mathrm{PE2-CH}{ }_{2} \mathrm{OH}$ ) and article 3 (50 mM PE3- $\left.\mathrm{CH}_{2} \mathrm{OH}\right)$. Reference glasses for each article with no gold nanoparticles were also made. The Largest Surface Plasmon Resonance (LSPR) is the peak wavelength of absorption corresponding to the longitudinal resonance in the bipyramidal gold nanoparticles. The LSPRs in this table are for the particles in solution and not bulk glass. For calculation of particle concentrations see [17].

\begin{tabular}{|c|c|c|c|}
\hline \multirow[b]{2}{*}{ Particle shape } & \multicolumn{2}{|c|}{ Concentration } & \multirow[b]{2}{*}{ Article } \\
\hline & Gold (mM) & Particle (nM) & \\
\hline \multirow{4}{*}{ Spheres $23 \mathrm{~nm}$} & 0.125 & 0.06 & $1,2,3$ \\
\hline & 0.25 & 0.13 & $1,2,3$ \\
\hline & 0.50 & 0.25 & $1,2,3$ \\
\hline & 1.00 & 0.5 & $1,2,3$ \\
\hline \multirow{5}{*}{ Spheres $45 \mathrm{~nm}$} & 0.031 & 0.006 & 1,3 \\
\hline & 0.063 & 0.013 & $1,2,3$ \\
\hline & 0.125 & 0.026 & $1,2,3$ \\
\hline & 0.25 & 0.052 & $1,2,3$ \\
\hline & 0.5 & 0.1 & $1,2,3$ \\
\hline \multirow{3}{*}{ Bipyramids LSPR $=640 \mathrm{~nm}$} & 0.063 & 0.29 & 1,2 \\
\hline & 0.125 & 0.58 & 1,2 \\
\hline & 0.25 & 1.15 & 1,2 \\
\hline \multirow{3}{*}{ Bipyramids LSPR $=700 \mathrm{~nm}$} & 0.063 & 0.12 & 1,2 \\
\hline & 0.125 & 0.24 & 1,2 \\
\hline & 0.25 & 0.48 & 1,2 \\
\hline \multirow{3}{*}{ Bipyramids LSPR $=770 \mathrm{~nm}$} & 0.063 & 0.048 & $1,2,3$ \\
\hline & 0.125 & 0.097 & $1,2,3$ \\
\hline & 0.25 & 0.19 & $1,2,3$ \\
\hline Reference & 0 & 0 & $1,2,3$ \\
\hline
\end{tabular}




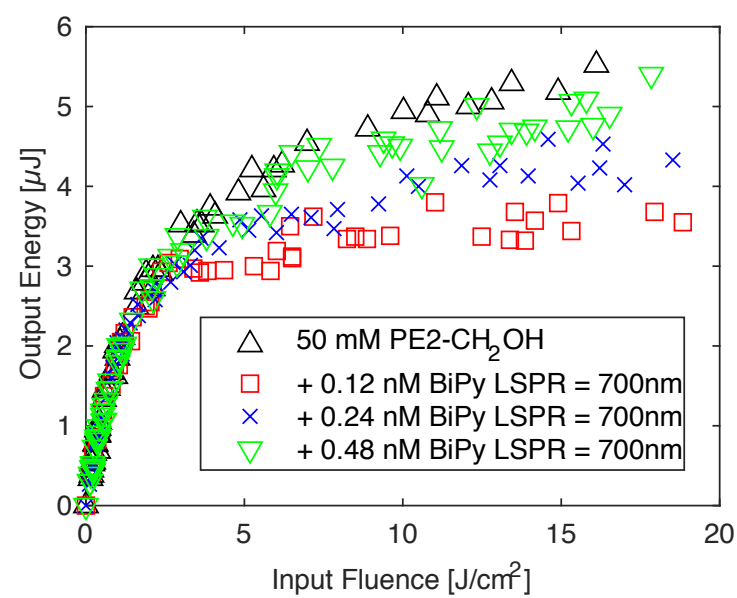

Figure 4.1. Optical power limiting measurement of MTEOS glasses doped with $50 \mathrm{mM}$ $\mathrm{PE} 2-\mathrm{CH}_{2} \mathrm{OH}$ and varying concentrations of bipyramidal gold nanoparticles with a largest surface plasmon resonance of $700 \mathrm{~nm}$ (as measured in solution) [18].

\subsubsection{Glasses with gold nanoparticles and $\mathrm{PE} 2-\mathrm{CH}_{2} \mathrm{OH}$}

The MTEOS glasses doped both with gold nanoparticles and $50 \mathrm{mM} \mathrm{PE} 2-\mathrm{CH}_{2} \mathrm{OH}$ showed at $600 \mathrm{~nm}$ lower optical power limiting clamping level for low concentrations of gold nanoparticles compared to no particles or high concentrations, see figure 4.1 [18]. At $532 \mathrm{~nm}$ a similar pattern was not found. As with the previous glasses, the UV-Vis measurements showed well defined plasmon peaks without any marked widening or shift with gold nanoparticle concentration. The luminescence spectra and phosphorescence lifetimes of the glasses showed no apparent systematic differences regarding to gold nanoparticle concentration or shape. ESA measurements in THF solution showed a larger absorption and a decrease in phosphorescence yield with gold nanoparticles, also phosphorescence lifetime decreased with more gold nanoparticles in the solution.

\subsubsection{Glasses with gold nanoparticles and $\mathrm{PE} 3-\mathrm{CH}_{2} \mathrm{OH}$}

The glasses doped with gold nanoparticles and $\mathrm{PE} 3-\mathrm{CH}_{2} \mathrm{OH}$ did not show any pattern of improvement of clamping level above noise level compared to the glasses only doped with $\mathrm{PE} 3-\mathrm{CH}_{2} \mathrm{OH}$ [19]. At $600 \mathrm{~nm}$ all $\mathrm{PE} 3-\mathrm{CH}_{2} \mathrm{OH}$ glasses showed a clamping level much lower than the $\mathrm{PE} 2-\mathrm{CH}_{2} \mathrm{OH}$ glasses. Secondly, the cut-off was very sharp. The UV-Vis spectra showed a wavelength shift with concentration of bipyramidal gold nanoparticles.

Phosphorescence lifetime measurements were not possible due to a lack of discernible phosphorescence peak. 


\subsection{Population Model}

To account for and explain the results reported in section 4.1, a model with predictive power had to be created to allow for the design of future composite chromophore/gold nanoparticle materials. Several questions had to be answered simultaneously, either by one mechanism or several acting together:

1. Why was there clamping level enhancement of $\mathrm{PE} 2-\mathrm{CH}_{2} \mathrm{OH}$ at $600 \mathrm{~nm}$ but not at $532 \mathrm{~nm}$ ?

2. Why was there optical power limiting at $532 \mathrm{~nm}$ but not at $600 \mathrm{~nm}$ for glasses only doped with gold nanoparticles? Why was performance better at $532 \mathrm{~nm}$ compared to glasses also doped with a chromophore?

3. Why was no second harmonic generation detected as expected for gold nanoparticles $[104,105]$ ?

4. Why was there only clearly noticeable enhancement for $\mathrm{PE} 2-\mathrm{CH}_{2} \mathrm{OH}$ but not for the $\mathrm{PE} 3-\mathrm{CH}_{2} \mathrm{OH}$ chromophore?

5. Why is there an enhancement at only low concentrations of nanoparticles? The doping concentrations of the gold nanoparticles corresponded to an average particle distance in the micrometer scale.

6. Why does the enhancement disappear at higher concentrations of gold nanoparticles?

7. Why didn't the enhancement correlate to any changes in luminescence spectra or phosphorescence lifetimes?

8. Why was there excited state absorption enhancement for $\mathrm{PE} 2-\mathrm{CH}_{2} \mathrm{OH}$ in solution together with gold nanoparticles?

9. Why was there signs of quenching in the phosphorescence decay times for $\mathrm{PE} 2-\mathrm{CH}_{2} \mathrm{OH}$ with increasing concentration of gold nanoparticles in solution?

These questions were able to discredit several hypotheses:

Quenching/rate changes The quenching hypothesis was weak since any large quenching or rate changes would have changed the photophysical measurement results (question 7) . Secondly, considering the low concentration of gold nanoparticles, it would be diffucult to influence large enough a percentage of the glass material considering the expected range $[51,74,80]$ of quenching (question 5). While resonances between chromophore fluorescence band and nanoparticle plasmon band can increase the interaction range [81, 82 ], the lack of enhancement of the clamping level at $532 \mathrm{~nm}$ excitation wavelength would be difficult to explain with this mechanism. Collisional quenching [51] can explain the quenching of phosphorescence in solution (question $9)$. 
Hot electrons A potential solution to the long range problem (question 5) would be excited electrons from the gold ${ }^{1}[106]$. This mechanism would be problematic to combine with question 4 and 1. It's difficult to see why any excited electrons would influence PE2- $\mathrm{CH}_{2} \mathrm{OH}$ but not $\mathrm{PE} 3-\mathrm{CH}_{2} \mathrm{OH}$. Secondly, the wavelength dependence would be difficult to explain considering both $532 \mathrm{~nm}$ and $600 \mathrm{~nm}$ being above the resonances of gold [107].

Superposition A combination of optical power limiting from chromophores and gold nanoparticles is an unlikely explanation considering question 2. A simple superposition is not compatible with the lowering of performance at $532 \mathrm{~nm}$ with the addition of a chromophore.

Linear field enhancement Considering the lack of enhancement at $532 \mathrm{~nm}$ (question 1) this was not a probable explanation. It is known that similar platinum acetylides' main mechanism around this wavelength is linear absorption followed by intersystem crossing into the triplet state, alternatively a forbidden direct transition into the triplet state (around $520 \mathrm{~nm}$ for PE2) [14, 59, 62].

Second harmonic generation An interesting solution to the questions above would be second harmonic generation from the gold nanoparticles. It would have explained the wavelength dependence due to the higher matrix absorption and lower chromophore absorption at 532/2 nm. Secondly, PE2 in solution has an absorption peak at $600 / 2 \mathrm{~nm}$ [14]. But no second harmonic generation was found (question 3).

Considering that at $600 \mathrm{~nm}$ the expected mechanism for reverse saturable absorption in similar platinum acetylides is two-photon absorption followed by intersystem crossing into the triplet state [59, 62] and that field enhancement of twophoton absorption has been reported in the literature [83, 108, 109], it is apt to investigate how a two-photon field enhancement model could answer the questions above:

1. At $532 \mathrm{~nm}$ the dominant mechanism is linear absorption followed by intersystem crossing or a forbidden direct linear absorption into the triplet state [14, $59,62]$. This would explain the lack of enhancement for green light.

2. An alternative mechanism not present or not dominant in glasses also doped with chromophores would be necessary to mesh well with a two-photon absorption enhancement model. Considering that the optical power limiting from gold nanoparticles in solution originates from non-linear scattering from microplasmas [21, 43], the high doping of chromophores might make it more difficult for microcracks to form in the glass. This hypothesis is yet to be investigated. A systematic exploration of laser damage to the filters was not possible with our current measurement setup.

3. Since no strong second harmonic generation was detected from the gold nanoparticles, this mechanism was not deemed probable.

\footnotetext{
${ }^{1}$ Idea from Mårten Armgarth.
} 
4. For reasoning why enhanced two-photon absorption will not influence the performance of PE3- $\mathrm{CH}_{2} \mathrm{OH}$ glasses as much, see section 4.2.2.

5. Two-photon absorption enhancement can be both powerful and long range. See section 4.2.1.

6. The dependence on $I^{2}$ for two-photon absorption is more sensitive than linear absorption $(\sim I)$. This means that any linear absorption before the focus have more impact, see section 4.2.3.

7. This mechanism does not require quenching. Secondly, the photophysical measurements were made at different wavelengths.

8. The excited state absorption measurements were performed by exciting the UV singlet absorption peak [18]. This question neither supports nor discredit the two-photon absorption enhancement model.

9. The quenching of chromophores in solution is different from when the chromophores are locked in a glass matrix. Moving chromophores and gold result in collisional quenching [51].

While the two-photon absorption enhancement model meshes well with earlier findings in the literature and at least at a superficial level explains the results, constructing a numerical population model to evaluate it at a qualitative level was considered necessary. Photophysical parameters were selected from the similar chromophores PE2 and PE3 (section 1.5.1).

\subsubsection{Two-photon field enhancement}

From equation $1.1 \mathrm{~b}$ we know that the amount of photons two-photon absorbed is linear to

$$
-\frac{\partial I}{\partial z} \sim \beta_{0} I^{2}
$$

where

$$
I=\eta I_{0}
$$

and $\beta_{0}$ is two-photon absorption coefficient of the chromophore. $\eta$ is the Tanabe field enhancement factor [12] from equation 1.6 and $I_{0}$ the intensity of the incoming laser pulse. An effective two-photon absorption coefficient can then be defined as

$$
\beta=\eta^{2} \beta_{0}
$$

giving

$$
-\frac{\partial I}{\partial z} \sim \beta I_{0}^{2}
$$

In the direction of maximum field enhancement 


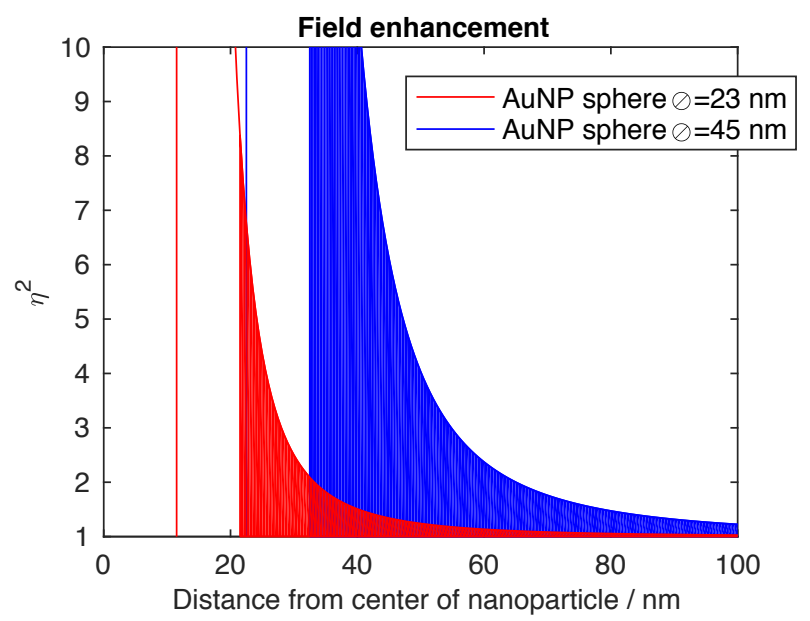

Figure 4.2. Field enhancement from gold nanoparticles of diameter $23 \mathrm{~nm}$ or $45 \mathrm{~nm}$ in $50 \mathrm{mM} \mathrm{PE} 2-\mathrm{CH}_{2} \mathrm{OH}$ doped MTEOS glass [18]. The x-axis is the direction of maximum enhancement. The two vertical lines are the surface of the gold nanoparticles. The part of the curves filled in are at the distances where field enhancement can be assumed to dominate quenching $[51,74,80]$.

$$
\eta=\left|1+2 \frac{a^{3}}{r^{3}} \frac{\epsilon_{1}-\epsilon_{m}}{\epsilon_{1}+2 \epsilon_{m}}\right|^{2}
$$

from equation 1.6 [12]. For $23 \mathrm{~nm}$ and $45 \mathrm{~nm}$ gold [110, 111] spheres in a $n=1.43$ material, the field enhancement at $600 \mathrm{~nm}$ wavelength is shown in figure 4.2 [18]. In the plot, only the enhancement further away than $10 \mathrm{~nm}$ from the gold surface is filled in as a conservative measure considering the quenching observed in solution (question 9).

\subsubsection{Absorption enhancement factor}

Applying this effective two-photon absorption into a population model (chapter 2) combined with photophysical parameters from similar platinum acetylides (section 1.5.1) it is possible to calculate the absorption $\alpha\left(\eta^{2}, t\right)$ from equation 2.11. The idea to feed a population model a field enhancement factor was taken from Fischer et. al's modelling of luminescence enhancement [13]. In an analogue manner an absorption enhancement factor can be defined as

$$
\gamma\left(\eta^{2}, t\right)=\frac{\alpha\left(\eta^{2}, t\right)}{\alpha(1, t)}
$$

Instead of the spatial variation of $\eta$, the time evolution $t$ of the reverse saturable absorption is investigated. The results for PE2 and PE3 (section 1.5.1) are shown 

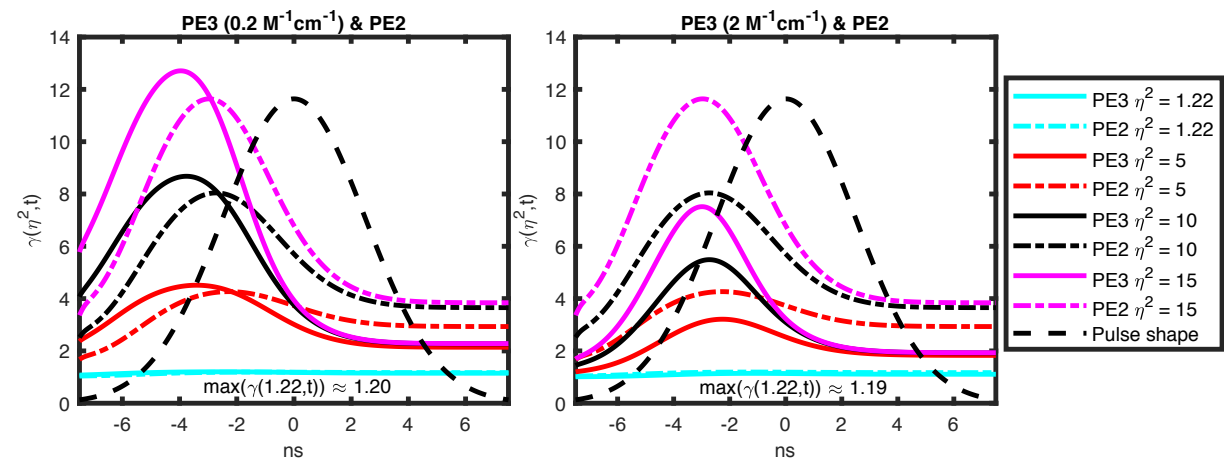

Figure 4.3. Absorption enhancement factor for a $5 \mathrm{~ns}, 10 \mathrm{~J} / \mathrm{cm}^{2}$ pulse [19]. PE2 and two potential variants of PE3 are investigated. Expected $\eta^{2}$ values selected from figure 4.2.

in figure 4.3. Since the linear absorbance of PE3 at $600 \mathrm{~nm}$ is not known two different values were selected, the same as PE2 or 10 times as much. A higher linear absorption would not be considered surprising considered the red-shift of the singlet absorption peak in PE3 compared to PE2 [14]. ${ }^{2}$

The enhancement for the PE2 model shows how the leading edge of the pulse more easily populate the triplet state in the presence of gold nanoparticles. After the leading edge of the pulse the triplet state is already populated enough, resulting in the overwhelming majority of the light being blocked. This explains the increased performance from co-doping with gold nanoparticles and $\mathrm{PE} 2-\mathrm{CH}_{2} \mathrm{OH}$.

The lower enhancement of the PE3 model with higher linear absorption compared to the PE2 model shows how an already high performing reverse saturable absorber will not get the same relative enhancement due to the highly absorbing triplet state already being populated quick enough. Considering the higher performance of $\mathrm{PE} 3-\mathrm{CH}_{2} \mathrm{OH}$ compared to $\mathrm{PE} 2-\mathrm{CH}_{2} \mathrm{OH}$ while measurement noise being comparable between the different series, it would not be impossible that the enhancement is hidden below the noise level of the measurement ${ }^{3}$.

\subsubsection{Linear absorption before the focal point}

It is a well known that having an absorbing medium in front of the focus in a non-linear material will reduce the optical power limiting effect $[16,19,112]$. The linear absorption before the focus can interfere with the non-linear scattering of nanodiamonds [113]. The losses from gold nanoparticles before the focus can be estimated to

$$
T_{A u N P}=\sqrt{\frac{T}{T_{0}}}
$$

\footnotetext{
${ }^{2}$ Idea from Mikael Lindgren.

${ }^{3}$ Idea from Mikael Lindgren.
} 
where $T$ is the transmittance of the glass and $T_{0}$ is the transmittance of a reference glass without any gold nanoparticles. The effective two-photon absorption coefficient can then be expressed by

$$
\beta=\eta^{2} T_{A u N P}^{2} \beta_{0}
$$

The $T_{A u N P}^{2}$ acts over the entire glass volume while $\eta^{2}$ is only strong near a gold nanoparticle. Considering that the estimated $T_{A u N P}^{2}$ values are between 0.97 to 0.76 for the glasses with highest concentration of gold nanoparticles, a cancellation of the $\eta^{2}$ improvement could be considered. However, spatially resolved modelling would be necessary to fully test the hypothesis of linear absorption loss before the focus.

\subsubsection{Potential pitfalls of the model}

While the two-photon enhancement model survived the qualitative test described above, it must be stressed that the numerical model has several issues that need to be explained in deeper detail.

- The photophysical values of PE2 and PE3 were measured in solution [10, 11, 14]. Secondly, the chromophores used in the glasses were functionalized with $\mathrm{CH}_{2} \mathrm{OH}$. The impact of the glass matrix has not been taken into account but for quenching of the triplet state (which had no impact since $1 \mu \mathrm{s}$ is much longer than the 5 ns laser pulse). This means that the photophysical parameters used only can be considered as coarse estimates.

- The linear absorption at $600 \mathrm{~nm}$ of $\mathrm{PE} 3-\mathrm{CH}_{2} \mathrm{OH}$ in the glass matrix is unknown. However, any other method for more efficient population of the triplet state, such as a forbidden $S_{0}$ to $T_{1}$ transition could replace the assumption of higher linear absorption.

- Excited state absorption in the singlet $\left(S_{1}\right)$ state is ignored and unknown. Ultra-fast transient absorption measurements would be necessary to acquire the necessary photophysical data.

- The model does not take into account the beam propagation, only a single point at the focus. To fully test the validity of this model, a spatial model with stochastic placement of gold nanoparticles would be necessary. This is especially necessary for modelling the interplay between linear absorption before the focus and two-photon absorption at it.

- The numerical model is intended as a test for the two-photon enhancement model. Other effects such as linear field enhancement, quenching etc. has not been included in it. To make such a test meaningful a more complicated spatial model would have to be constructed.

- To fully test the model, a greater range of chromophores with varying twophoton absorption, linear absorption, intersystem crossing rate and excited 
state absorption need to be investigated, preferably in solution to allow for greater variation. ${ }^{4}$

While the qualitative numerical model is useful as a first test for the twophoton absorption enhancement hypothesis, it needs further work to give more quantitative predictions.

The assumption of higher linear absorption in $\mathrm{PE} 3-\mathrm{CH}_{2} \mathrm{OH}$ in MTEOS glass at $600 \mathrm{~nm}$ creates an unwanted free variable that reduces the persuasive power of the model. The shifting plasmon resonance wavelength with different concentration of bipyramids in the $\mathrm{PE} 3-\mathrm{CH}_{2} \mathrm{OH}$ glasses (section 4.1.3) begets the question if the changing of this variable is an attempt to shoe-horn an experiment into a theoretical model. A shift in plasmon resonance wavelength could indicate that the gold nanoparticles were not evenly distributed in the glass [3, 4, 78, 79]. Though a similar shift is not seen for the spherical nanoparticles. Secondly a marked widening of the absorption peaks with increased nanoparticle concentration due to random group sizes is not seen.

\footnotetext{
${ }^{4}$ Idea from Mikael Lindgren.
} 


\section{CHAPTER 5}

Fluorene molecules

This chapter is a summary of article 5. Three multi-branched fluorene molecules were designed and synthesized by C. Andraud and co-workers at ENS-LYON to investigate the effect of different central InterSystem Crossing (ISC) moieties on highly two-photon absorbing (2PA) molecules, see section 1.5.2, figure 1.7, figure 1.8 and figure 1.9. Molecule A's central moiety was a benzene ring, molecule B's was para-dibromobenzene and molecule C a Platinum(II)-alkynyl unit. The purpose was to test the 2PA field enhancement model from section 4.2 and to investigate the effect of different centrally placed ISC promoting moieties.

While the unexpected results (section 5.1) were neither useful to strengthen nor weaken the 2PA field enhancement hypothesis, conclusions could be drawn pointing towards an OPL design strategy balancing the ISC-rate to singlet Excited State Absorption (ESA) (section 5.2).

\subsection{Results and Discussion}

Prior to the wavelength scanned Optical Power Limiting (OPL) measurements, photophysical measuremnts had shown:

1. Molecule $\mathrm{C}$ had the most redshifted UV-absorption peak at around $400 \mathrm{~nm}$ in its linear absorption spectrum of the three molecules.

2. Luminescence spectra before and after Argon purging indicated strong phosphorescence for molecule $\mathrm{C}$, weak phosphorescence for molecule B and barely none for molecule A.

3. Microsecond ESA measurements had shown the strongest signal for molecule $\mathrm{B}$, strong for molecule $\mathrm{C}$ and comparatively weak for molecule A. Also, the 


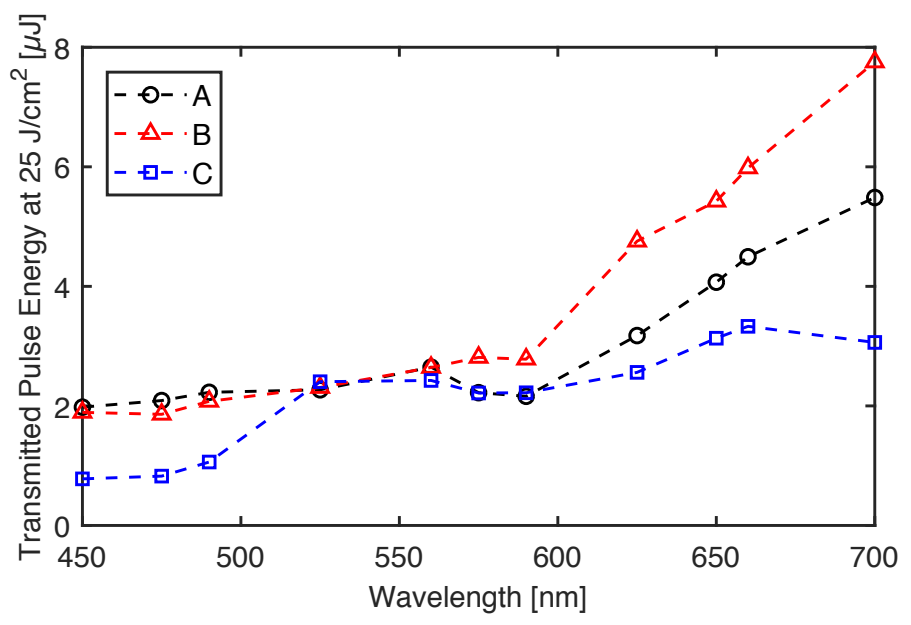

Figure 5.1. Nanosecond OPL spectra through the visible spectrum for molecule A, B and $\mathrm{C}[20]$. Output pulse energy at $25 \mathrm{~J} \mathrm{~cm}^{-3}$ input fluence according to a linear fit of datapoints above $20 \mathrm{~J} \mathrm{~cm}^{-3}$, i.e. a pseudo cut-off level.

ground state bleaching for molecule A was small compared to the two other molecules.

These three findings taken together gave the conclusion that molecule A's triplet state was poorly populated due to its lack of a central ISC moiety. Though, the hypothesis that molecule A would show poor OPL performance was proven wrong, see figure 5.1. In the red wavelength region it showed better performance than molecule B but worse than molecule C. Molecule A showed a low flat 2PA cross-section in the near infra-red. In the green wavelength region it showed similar OPL performance to both molecule B and C. In the blue wavelength region, similar to molecule B.

Many of the OPL measurements for molecule B showed a dip in output pulse energy at intermediate fluence levels. This indicate a non-linearity in the population of the excited state. Due to its low luminescence, no 2PA cross-sections were available. For steady state (continous wave) models, saturable absorption in the singlet state can cause a depression in transmittance at intermidiary intesity levels [88]. But due to the 3 to 5 ns pulse width for the OPL measurements, system behaviour is expected to be very different.

The superiority of molecule $\mathrm{C}$ in the blue wavelength region was expected due to the proximity to its absorption edge. Regarding its performance in the red wavelength region, Pt-acetylides are known to show 2PA [10, 11, 59, 62]. Secondly, near infra-red 2PA measurements showed that molecule $\mathrm{C}$ showed considerably increased 2PA towards $700 \mathrm{~nm}$ (the short wavelength limit for the $2 \mathrm{PA}$ measurements).

While 2PA spectra for all three molecules were not available in the visible spectrum, pure $2 \mathrm{PA}$ is not expected to be the cause of molecule A's performance. 

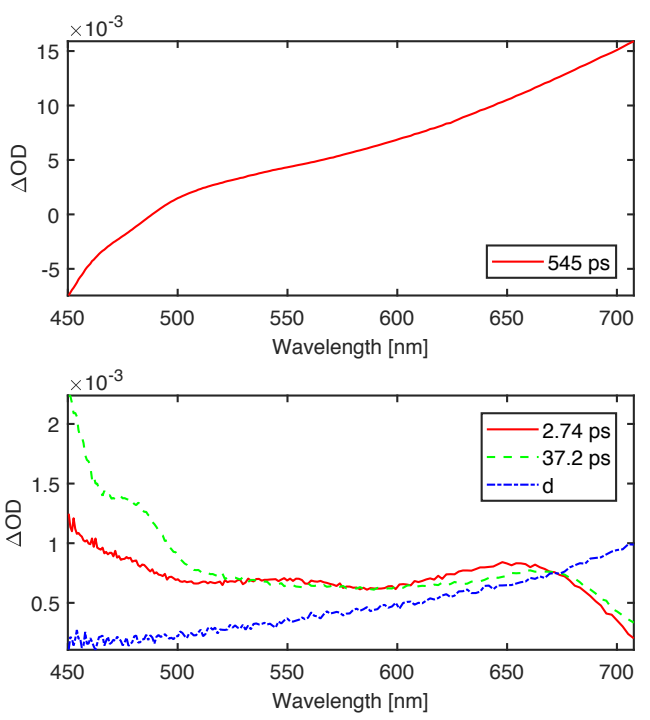

Figure 5.2. Spectral basis vectors according to equation 3.2.4 for molecule A [20].

Numerical simulations by Glimsdal showed that extremely large 2PA cross-sections would be necessary to single-handily drive OPL performance, but in combination with ESA it is a potent multiplier [40].

\subsubsection{Ultra-fast transient absorption measurements}

To give an understanding of the origin of molecule A's OPL performance, ultrafast transient absorption measurements were needed. Molecule A showed a large amplitude decay with a $545 \mathrm{ps}$ lifetime, see figure 5.2. For nanosecond pulses the OPL performance during the rising edge of the pulse has the most impact on transmitted pulse energy [16]. This lifetime is therefore long enough to be relevant for nanosecond pulses. In the blue wavelength region the amplitude was negative, indicating fluorescence (singlet state) ${ }^{1}$. 2,2'-(9,9-dehexyl) bifluorene is known to have a singlet exited state lifetime of $450 \mathrm{ps}$ [49]. A similar but more short-lived decay was found for molecule B. This could be explained as molecule B's excited singlet state being depopulated by ISC. In this case being counterproductive considering molecule A's better OPL performance.

\subsection{Conclusions}

The ultra-fast transient absorption measurement were able to resolve the apparent contradiction between the microsecond ESA measurements and the wavelength

\footnotetext{
${ }^{1}$ Idea from I. Minda.
} 
scanned OPL measurements. Singlet RSA was behind molecule A's OPL performance, possibly in conjunction with $2 \mathrm{PA}$.

The addition of an ISC moiety in molecule B actually turned out to be counterproductive. While more in depth studies are necessary to fully understand the photo-kinetics of the molecules, the results hint on a design strategy: the ISC into the long lived triplet state of molecules with large singlet ESA needs be balanced between initial high attenuation in the singlet state and efficient population of the long lived triplet state. 


\section{CHAPTER 6}

\section{Conclusions}

The work building up to this thesis can be considered to be of four parts. The investigation of gold nanoparticle and $\mathrm{Pt}$ (II)-acetylide doped glasses resulted in 3 publications. Secondly, the tutorial article on how to evaluate promising Optical Power Limiting (OPL) chromophores. Thirdly, the investigation of the three multibranched fluorene molecules using the techniques and thinking of paper 4 . The fourth part being the work on interpreting numerical population model results by time-resolved attenuation coefficient improvement functions, a tool created to qualitatively explain the different OPL performance between samples.

The gold nanoparticle articles showed how 2PA field enhancement can enhance OPL performance, but for an already highly efficient OPL molecule further enhancement could not be achieved.

For molecule A of the multi-branched fluorene chromophores, the addition of an InterSystem Crossing (ISC) promoter was not necessary due to the already high singlet ESA. This hinted on a design strategy were the ISC time was balanced between high attenuation from the excited singlet state and the extended lifetime of a triplet state with weaker attenuation.

In the tutorial article it is explained how to characterize OPL molecules, both experimentally and numerically. By first performing photophysical measurements, relevant parameters can be entered into a numerical population model. Then the time-resolved attenuation coefficient improvement function (equation 2.7) can be used to explore the sensitivity of the molecule to changes in parameters.

This thesis can be summed up in a single sentence:

"The important question is not which parameters are most important to OPL performance, but when they are." 


\section{CHAPTER 7}

Errata

Minor errors in the articles have been found after publication.

Dispersion and self-orientation of gold nanoparticles in sol-gel hybrid silica - optical transmission properties

- The reference detector was a PE9-SH not PE9.

- The gallilean telescope was $2.66 \mathrm{x}$ not $2 \mathrm{x}$.

Long distance enhancement of nonlinear optical properties using low concentration of plasmonic nanostructures in dye doped monolithic solgel materials

- The pure two-photon absorption without reverse saturable absorption was overestimated in the absorption enhancement factor by $\eta$. Secondly, all the linear absorption was underestimated by $\ln 10$. The correct plot is shown in figure 7.1. Any changes to the discussion or conclusion is not necessary since the relevant qualitative behaviour of the model was the same.

All three gold nanoparticle articles had a weakness in experimental methodology that risks giving the impression of lower noise in the optical power limiting measurements than there should be. Due to the stochastic nature of input laser pulse energy, an excessive number of pulses were sometimes necessary to get an even distribution of points along the x-axis. To avoid giving a false impression of a lower cut-off level due to a non-symmetric variation in output energy, a small number of points were cut from below. A $(0,0)$ data point had also been added. We have changed our laboratory's experimental procedures to avoid such issues in the future. 


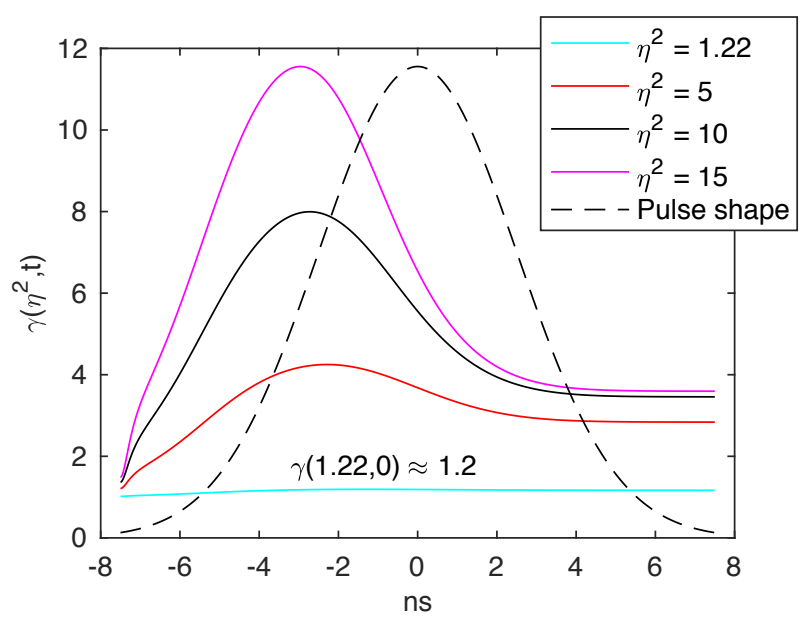

Figure 7.1. Correction to the absorption enhancement factor in article 2.

\section{How to assess good candidate molecules for self-activated optical power limiting}

- An unfortunate grammatical error reversed the meaning of a sentence in the transient absorption section:

"The advantage of the OPL measurement is that it gives directly some important parameters for calculating the performance: the spectral extension and extinction coefficient of the excited triplet state as well as its lifetime." should be

"The advantage compared to the OPL measurement is that it directly gives some important parameters for calculating the performance: the spectral shape of the extinction coefficient of the excited triplet state as well as its lifetime.". 


\section{Bibliography}

[1] H. Lundén. "Sol-Gel Glasses Doped with Pt-Acetylides and Gold Nanoparticles for Enhanced Optical Power Limiting". Licentiate Thesis. Linköping University, 2017.

[2] D. Chateau et al. "Silica hybrid sol-gel materials with unusually high concentration of ptorganic molecular guests: Studies of luminescence and nonlinear absorption of light". In: ACS Appl. Mater. Interfaces 4.5 (2012), pp. 2369-2377.

[3] J. Zhang and L. Zhang. "Nanostructures for surface plasmons". In: Adv. Opt. Photonics 4.2 (2012), p. 157.

[4] N. J. Halas et al. "Plasmons in strongly coupled metallic nanostructures". In: Chem. Rev. 111.6 (2011), pp. 3913-3961.

[5] R. West, Y. Wang, and T. Goodson. "Nonlinear absorption properties in novel gold nanostructured topologies". In: J. Phys. Chem. B 107.15 (2003), pp. 3419-3426.

[6] S. Prahl. Mie Scattering Calculator - http://omlc.org/calc/mie_calc.html (Retrieved 2016-12-15).

[7] L. W. Tutt and T. F. Boggess. "A review of optical limiting mechanisms and devices using organics, fullerenes, semiconductors and other materials". In: Prog. Quantum Electron. 17.4 (1993), pp. 299-338.

[8] L. Polavarapu et al. "Optical-limiting properties of oleylamine-capped gold nanoparticles for both femtosecond and nanosecond laser pulses". In: ACS Appl. Mater. Interfaces 1.10 (2009), pp. 2298-2303.

[9] E. W. V. Stryland and M. Sheik-Bahae. "Z-Scan Measurements of Optical Nonlinearities". In: Charact. Tech. Tabul. Org. Nonlinear Mater. Ed. by M. G. Kuzyk and C. W. Dirk. 3. Marcel Dekker, Inc., 1998, pp. 655-692. 
[10] M. G. Vivas et al. "Interpreting Strong Two-Photon Absorption of PE3 Platinum Acetylide Complex: Double Resonance and Excited State Absorption". In: ACS Photonics 1.2 (2014), pp. 106-113.

[11] M. G. Vivas et al. "Understanding the two-photon absorption spectrum of PE2 platinum acetylide complex". In: J. Phys. Chem. A 118.30 (2014), pp. 5608-5613.

[12] K. Tanabe. "Field enhancement around metal nanoparticles and nanoshells: A systematic investigation". In: J. Phys. Chem. C 112.40 (2008), pp. 1572115728.

[13] S. Fischer et al. "Plasmon enhanced upconversion luminescence near gold nanoparticles - simulation and analysis of the interactions". In: Opt. Express 20.1 (2012), pp. 271-282. arXiv: 1110.6072.

[14] J. E. Rogers et al. "Photophysical Characterization of a Series of Platinum ( II ) -Containing Phenyl-Ethynyl Oligomers". In: J. Phys. Chem. A 106 (2002), pp. 10108-10115.

[15] D. K. Hopen. "Spectroscopic characterization and performance of novel triplet state enhanced molecules for optical power limiting". Master's Thesis. NTNU, 2018.

[16] H. Lundén et al. "How to assess good candidate molecules for self-activated optical power limiting". In: Opt. Eng. 57.03 (2018), p. 1.

[17] H. Lundén et al. "Dispersion and self-orientation of gold nanoparticles in sol-gel hybrid silica - Optical transmission properties". In: J. Mater. Chem. C 3.5 (2015), pp. 1026-1034.

[18] D. Chateau et al. "Long Distance Enhancement of Nonlinear Optical Properties Using Low Concentration of Plasmonic Nanostructures in Dye Doped Monolithic Sol-Gel Materials". In: Adv. Funct. Mater. 26 (2016), pp. 60056014 .

[19] H. Lundén et al. "Efficient reverse saturable absorption of sol-gel hybrid plasmonic glasses". In: Opt. Mater. (Amst). 69 (2017), pp. 134-140.

[20] H. Lundén et al. "An Optical Power Limiting and ultrafast photophysics investigation of a series of multi-branched heavy atom substituted fluorene molecules". In: To Be Submitt. (2019).

[21] D. Dini, M. J. F. Calvete, and M. Hanack. "Nonlinear Optical Materials for the Smart Filtering of Optical Radiation". In: Chem. Rev. 116.22 (2016), pp. 13043-13233.

[22] R. Westlund et al. "Efficient nonlinear absorbing platinum(II) acetylide chrompphores in solid PMMA matrices". In: Adv. Funct. Mater. 18.13 (2008), pp. 1939-1948.

[23] G. L. Wood et al. "Evaluation of passive optical limiters and switches". In: SPIE Vol. 1105, Mater. Opt. Switch. Isol. Limiters. 1989, pp. 154-180.

[24] G. Ritt, S. Dengler, and B. Eberle. "Protection of optical systems against laser radiation". In: Proc. SPIE. Vol. 7481. 2009, 74810U. 
[25] J. Staromlynska et al. "Nonlinear Optical Materials for Switching and Limiting". In: Proc. SPIE 2229. 1994, p. 59.

[26] C. J. Campbell et al. "The threshold of the retina to damage by laser energy". In: Arch. Ophthalmol. 76.3 (1966), pp. 437-442.

[27] J Marshall, A. M. Hamilton, and A. C. Bird. "Histopathology of ruby and monkey and human retina laser lesions in". In: Br. J. Ophthalmol. 59 (1975), pp. 610-630.

[28] J. Marshall and A. C. Bird. "A comparative histopathological study of argon and krypton laser irradiations of the human retina". In: Br. J. Ophthalmol. 63 (1979), pp. 657-668.

[29] J. Marshall. "The safety of laser pointers : myths and realities". In: Br. J. Ophthalmol. 82 (1998), pp. 1335-1338.

[30] B. Seet and T. Y. Wong. "Military laser weapons : Current controversies". In: Ophthalmic Epidemiol. 8.4 (2001), pp. 215-226.

[31] A. Eriksson. "Modeling and Characterization of Nonlinear Materials for Protection of Optical Sensors". PhD Thesis. Linköping University, 2001.

[32] F. Meinardi et al. "Highly efficient large-area colourless luminescent solar concentrators using heavy-metal-free colloidal quantum dots". In: Nat. Nanotechnol. 10.10 (2015), pp. 878-885.

[33] G. Ritt and B. Eberle. "Protection concepts for optronical sensors against laser radiation". In: Proc. SPIE. Vol. 8185. 2011, 81850G.

[34] M. J. Miller, A. G. Mott, and B. P. Ketchel. "General optical limiting requirements". In: Proc. SPIE Vol. 3472, Nonlinear Opt. Liq. Power Limiting Imaging. 1998.

[35] A. Donval et al. "Optical power control filters: from laser dazzling to damage protection". In: Proc. SPIE. Vol. 8257. 2012, p. 82570X.

[36] G. Lindh, ed. Arbetarskyddsstyrelsens författningssamling: LASER AFS 1994:8. Solna: Arbetarskyddsstyrelsen, 1994.

[37] M. Sheik-Bahae et al. "Sensitive Measurements of Optical Nonlinearities Using a Single Beam". In: IEEE J. Quantum Electron. 26.4 (1990), pp. 760769 .

[38] P. B. Chapple et al. "Single-Beam Z-Scan: Measurement Techniques and Analysis". In: J. Nonlinear Opt. Phys. Mater. 06.03 (1997), pp. 251-293. arXiv: arXiv:1011.1669v3.

[39] B. F. Schutz. A first course in general relativity. Cambridge: Cambridge University Press, 1985.

[40] E. Glimsdal. "Spectroscopic characterization of some platinum acetylide molecules for optical power limiting applications". PhD Thesis. Norwegian University of Science and Technology, 2009.

[41] H. Arwin. Thin Film Optics and Polarized Light. the Flavus. Linköping, 2015. 
[42] O. Ostroverkhova and W. E. Moerner. "Organic Photorefractives : Mechanisms , Materials , and Applications". In: Chem. Rev. 104 (2004), pp. 32673314 .

[43] L. François et al. "Optical Limitation induced by Gold Clusters. 1. Size Effect". In: J. Phys. Chem. B 104.26 (2000), pp. 6133-6137.

[44] R. B. Miles, W. R. Lempert, and J. N. Forkey. "Laser rayleigh scattering". In: Meas. Sci. Technol. 12 (2001), R33-R51.

[45] M. Rashidian Vaziri et al. "Investigating the extrinsic size effect of palladium and gold spherical nanoparticles". In: Opt. Mater. (Amst). 64 (2017), pp. 413-420.

[46] K. Mansour and E. W. V. Stryland. "Nonlinear optical properties of carbonblack suspensions (ink)". In: J. Opt. Soc. Am. B 9.7 (1992), pp. 1100-1109.

[47] A. Yariv. Quantum Electronics. 3:d. John Wiley \& Sons, Inc., 1989.

[48] S. Hirata et al. "Large reverse saturable absorption under weak continuous incoherent light." In: Nat. Mater. 13.10 (2014), pp. 938-46.

[49] Y. Morel et al. "Two-photon absorption and optical power limiting of bifluorene molecule". In: J. Chem. Phys. 114.12 (2001), pp. 5391-5396.

[50] C. Li et al. "Investigation of Two-Photon Absorption Induced Excited State Absorption in a Fluorenyl-Based Chromophore". In: (2009), pp. 1573015733.

[51] J. R. Lakowicz. Principles of Fluorescence Spectroscopy. Third Edit. New York: Springer Science+Business Media, LLC, 2006.

[52] G. Schneider et al. "Distance-dependent fluorescence quenching on gold nanoparticles ensheathed with layer-by-layer assembled polyelectrolytes". In: Nano Lett. 6.3 (2006), pp. 530-536.

[53] E Dulkeith et al. "Fluorescence quenching of dye molecules near gold nanoparticles: radiative and nonradiative effects." In: Phys. Rev. Lett. 89.20 (2002), p. 203002.

[54] J. C. Ostrowski et al. "Enhancement of phosphorescence by surface-plasmon resonances in colloidal metal nanoparticles: The role of aggregates". In: $A d v$. Funct. Mater. 16.9 (2006), pp. 1221-1227.

[55] D. A. Oulianov et al. "Investigation of benzoporphyrin and azulenic compounds by two-dimensional Z-scan technique". In: Nonlinear Opt. Liq. Power Limiting Imaging. Vol. 3472. 1998, pp. 98-105.

[56] E. Hecht. Optics. Fourth Edi. San Francisco: Pearson Education, Inc., 2002.

[57] R. C. Hollins. "Optical Limiters: Spatial, temporal, and spectral effects". In: Nonlinear Opt. 21 (1999), pp. 49-61.

[58] M. A. Cagigas, P. J. Valle, and M. P. Cagigal. "Super-Gaussian apodization in ground based telescopes for high contrast coronagraph imaging". In: Opt. Express 21.10 (2013), pp. 12744-12756. 
[59] C. Liao et al. "Organoplatinum chromophores for application in highperformance nonlinear absorption materials". In: ACS Appl. Mater. Interfaces 3.9 (2011), pp. 3225-3238.

[60] Y. Bretonnière and C. Andraud. "Chromophores for Optical Power Limiting". In: Photosensit. Med. Environ. Secur. Ed. by T. Nyokong and V. Ahsen. Heidelberg: Springer Netherlands, 2012, pp. 619-654.

[61] J. E. Rogers et al. "Platinum acetylide two-photon chromophores". In: Inorg. Chem. 46.16 (2007), pp. 6483-6494.

[62] T. J. McKay, J. A. Bolger, and J. Staromlynska. "Linear and nonlinear optical properties of platinum-ethynyl". In: Appl. Phys. B 108.13 (1998), pp. 5537-5541.

[63] P. Lind et al. "Structural, photophysical, and nonlinear absorption properties of trans-Di-arylalkynyl platinum(II) complexes with phenyl and thiophenyl groups". In: J. Phys. Chem. A 111.9 (2007), pp. 1598-1609.

[64] E. E. Silverman et al. "The triplet state in Pt-acetylide oligomers, polymers and copolymers". In: Coord. Chem. Rev. 249.13-14 (2005), pp. 1491-1500.

[65] K. Glusac et al. "Triplet excited state in platinum-acetylide oligomers: Triplet localization and effects of conformation". In: J. Phys. Chem. B 111.5 (2007), pp. 929-940.

[66] C. Girardot et al. "Ruthenium ( II ) Complexes for Two-Photon AbsorptionBased Optical Power Limiting". In: Ii (2008), pp. 1531-1535.

[67] G. Zhao et al. "Controllable preparation and near infrared optical limiting properties of fluorene-containing polyacetylenes". In: J. Appl. Polym. Sci. 135.18 (2018).

[68] Q. Zheng et al. "Synthesis, Characterization, Two-Photon Absorption , and Optical Limiting Properties of Ladder-Type Oligo-p-phenylene-Cored Chromophores". In: Adv. Funct. Mater. 18 (2008), pp. 2770-2779.

[69] S. A. Kurhuzenkau et al. "Electronic Nature of Nonlinear Optical Properties of a Symmetrical Two-Photon Absorbing Fluorene Derivative: Experimental Study and Theoretical Modeling". In: (2018).

[70] T.-C. Lin et al. "Two-photon absorption and optical power limiting properties in femtosecond regime of novel multi-branched chromophores based on tri-substituted olefinic scaffolds". In: J. Mater. Chem. 19.38 (2009), pp. 7075-7080.

[71] A. Triadon et al. "Linear and Third-Order Nonlinear Optical Properties of $\mathrm{Fe}(\eta 5$-C5Me5)( $\kappa 2$-dppe)- and trans-Ru( $\kappa 2$-dppe)2-Alkynyl Complexes Containing 2-Fluorenyl End Groups". In: Organometallics ASAP (2018).

[72] P.-H. Lanoë et al. "Influence of bromine substitution pattern on the singlet oxygen generation efficiency of two-photon absorbing chromophores". In: Org. Biomol. Chem. 10.31 (2012), pp. 6275-6278. 
[73] R. Zieba et al. "Preparation of functional hybrid glass material from platinum (II) complexes for broadband nonlinear absorption of light". In: $A d v$. Funct. Mater. 19.2 (2009), pp. 235-241.

[74] S. Eustis and M. a. El-Sayed. "Why gold nanoparticles are more precious than pretty gold: noble metal surface plasmon resonance and its enhancement of the radiative and nonradiative properties of nanocrystals of different shapes." In: Chem. Soc. Rev. 35.3 (2006), pp. 209-217. arXiv: NIHMS150003.

[75] B. T. Draine and P. J. Flatau. "Discrete-dipole approximation for scattering calculations". In: J. Opt. Soc. Am. A 11.4 (1994), pp. 1491-1499.

[76] V. Myroshnychenko et al. "Modelling the optical response of gold nanoparticles." In: Chem. Soc. Rev. 37.9 (2008), pp. 1792-1805.

[77] D Chateau et al. "From gold nanobipyramids to nanojavelins for a precise tuning of the plasmon resonance to the infrared wavelengths: experimental and theoretical aspects." In: Nanoscale 7.5 (2015), pp. 1934-1943.

[78] P. K. Jain, S. Eustis, and M. A. El-Sayed. "Plasmon coupling in nanorod assemblies: Optical absorption, discrete dipole approximation simulation, and exciton-coupling model". In: J. Phys. Chem. B 110.37 (2006), pp. 1824318253.

[79] K Su, Q Wei, and X Zhang. "Interparticle Coupling Effects on Plasmon Resonances of Nanogold Particles". In: (2003).

[80] P. Anger, P. Bharadwaj, and L. Novotny. "Enhancement and quenching of single-molecule fluorescence". In: Phys. Rev. Lett. 96.11 (2006), pp. 3-6.

[81] C. S. Yun et al. "Nanometal surface energy transfer in optical rulers, breaking the FRET barrier". In: J. Am. Chem. Soc. 127.9 (2005), pp. 3115-3119.

[82] S. Mayilo et al. "Long-range fluorescence quenching by gold nanoparticles in a sandwich immunoassay for cardiac troponin T". In: Nano Lett. 9.12 (2009), pp. 4558-4563.

[83] S. T. Sivapalan et al. "Plasmonic enhancement of the two photon absorption cross section of an organic chromophore using polyelectrolyte-coated gold nanorods". In: Langmuir 28.24 (2012), pp. 9147-9154.

[84] J. Staromlynska, T. J. McKay, and P. Wilson. "Broadband optical limiting based on excited state absorption in Pt:ethynyl". In: J. Appl. Phys. 88.4 (2000), p. 1726.

[85] T Xia et al. "Optimization of optical limiting devices based on excited-state absorption." In: Appl. Opt. 36.18 (1997), pp. 4110-22.

[86] A. Eriksson, K. Bertilsson, and M. Lindgren. "Simulation of beam propagation with time-dependent nonlinear processes in optical limiting applications". In: Synth. Met. 127.1-3 (2002), pp. 147-150.

[87] Q. Miao et al. "Dynamical Propagation of Nanosecond Pulses in Naphthalocyanines and Phthalocyanines". In: Chem. Phys. (2016). 
[88] A. Rao. "Comparison of rate equation models for nonlinear absorption". In: Optik (Stuttg). 158 (2018), pp. 652-663.

[89] T. J. Mckay et al. "Cross sections for excited-state absorption in a Pt : ethynyl complex". In: J. Opt. Soc. Am. B 18.3 (2001), pp. 358-362.

[90] Y Morel et al. "Optical power limiting properties of organic crystals and nanocrystals in an f/5 optical system". In: Synth. Met. 109 (2000), pp. 215218 .

[91] D. B. James and K. J. McEwan. "Bubble and Refractive processes in carbon suspensions". In: Nonlinear Opt. 21 (1999), pp. 377-389.

[92] D. Vincent and J. Cruickshank. "Optical limiting with C60 and other fullerenes". In: Appl. Opt. 36.30 (1997), pp. 7794-7798.

[93] F. E. Hernández et al. "Viscosity dependence of optical limiting in carbon black suspensions." In: Appl. Opt. 41.6 (2002), pp. 1103-7.

[94] X. Zheng, M. Feng, and H. Zhan. "Giant optical limiting effect in Ormosil gel glasses doped with graphene oxide materials". In: J. Mater. Chem. C 1.41 (2013), p. 6759.

[95] E. Glimsdal et al. "Excited states and two-photon absorption of some novel thiophenyl Pt(II)-ethynyl derivatives". In: J. Phys. Chem. A 111.2 (2007), pp. 244-250.

[96] E. Glimsdal et al. "Triplet Excited States of Some Thiophene and Triazole Substituted Platinum ( II ) Acetylide Chromophores". In: J. Phys. Chem. A 113.14 (2009), pp. 3311-3320.

[97] G. J. Zhou et al. "Optical power limiters based on colorless di-, oligo-, and polymetallaynes: Highly transparent materials for eye protection devices". In: Adv. Funct. Mater. 17.6 (2007), pp. 963-975.

[98] M. Lindgren et al. "Electronic states and phosphorescence of dendron functionalized platinum(II) acetylides". In: J. Lumin. 124.2 (2007), pp. 302310 .

[99] W. H. Melhuish. "QUANTUM EFFICIENCIES OF FLUORESCENCE OF ORGANIC SUBSTANCES: EFFECT OF SOLVENT AND CONCENTRATION OF THE FLUORESCENT SOLUTE". In: J. Phys. Chem. 65.2 (1961), pp. 229-235.

[100] M. A. Albota, C. Xu, and W. W. Webb. "Two-photon fluorescence excitation cross sections of biomolecular probes from 690 to $960 \mathrm{~nm}$ ". In: Appl. Opt. 37.31 (1998), pp. 7352-7356.

[101] G. Porter. "Flash photolysis and spectroscopy A new method for the study of free radical reactions". In: Proc. R. Soc. London 200 (1950), pp. 284-300.

[102] G. Ramakrishna et al. "Ultrafast intersystem crossing: Excited state dynamics of platinum acetylide complexes". In: J. Phys. Chem. C 113.3 (2009), pp. 1060-1066. arXiv: arXiv:1011.1669v3.

[103] J. S. Zugazagoitia et al. "Relaxation in the Triplet Manifold of 1-Nitronaphthalene Observed by Transient Absorption Spectroscopy". In: (2009), pp. 805-810. 
[104] J. Butet et al. "Optical second harmonic generation of single metallic nanoparticles embedded in a homogeneous medium". In: Nano Lett. 10.5 (2010), pp. 1717-1721.

[105] A. Capretti et al. "Multipolar second harmonic generation from planar arrays of Au nanoparticles." In: Opt. Express 20.14 (2012), p. 15797.

[106] K. Appavoo et al. "Ultrafast phase transition via catastrophic phonon collapse driven by plasmonic hot-electron injection". In: Nano Lett. 14.3 (2014), pp. 1127-1133.

[107] D. Barchiesi and T. Grosges. "Fitting the optical constants of gold, silver, chromium, titanium, and aluminum in the visible bandwidth". In: $J$. Nanophotonics 8.1 (2014), p. 83097.

[108] I. Cohanoschi and F. E. Hernández. "Surface plasmon enhancement of twoand three-photon absorption of hoechst 33258 dye in activated gold colloid solution". In: J. Phys. Chem. B 109.30 (2005), pp. 14506-14512.

[109] J. Zhang et al. "Enhancement of two-photon absorption and photoinduced birefringence in methyl orange by Au nanoparticles". In: Opt. Laser Technol. 43.5 (2011), pp. 974-977.

[110] A. D. Rakic et al. "Optical properties of metallic films for vertical-cavity optoelectronic devices." In: Appl. Opt. 37.22 (1998), pp. 5271-83.

[111] M. N. Polyanskiy. Refractive Index Database http://refractiveindex.info/ (Retrieved 2016-12-15).

[112] D. J. Hagan et al. "Optimization of reverse saturable absorber limiters: material requirements and design considerations". In: Mater. Res. Soc. Symp. Proc. 374. 1995, pp. 161-172.

[113] V. V. Vanyukov et al. "Concentration dependence of the optical limiting and nonlinear light scattering in aqueous suspensions of detonation nanodiamond clusters". In: Opt. Mater. (Amst). 37.C (2014), pp. 218-222. 


\section{Papers}

The papers associated with this thesis have been removed for copyright reasons. For more details about these see:

http://urn.kb.se/resolve?urn=urn:nbn:se:liu:diva-156612 


\section{FACULTY OF SCIENCE AND ENGINEERING}

Linköping Studies in Science and Technology, Dissertation No. 1979, 2019 Department of Physics, Chemistry and Biology (IFM)

Linköping University

SE-581 83 Linköping, Sweden

wwW.liu.se 